\title{
Potential Effects of COVID-19 on Cytochrome P450-Mediated Drug Metabolism and Disposition in Infected Patients
}

\author{
Subrata Deb ${ }^{1}$ D $\cdot$ Scott Arrighi ${ }^{1}$ \\ Published online: 4 February 2021 \\ (c) The Author(s), under exclusive licence to Springer Nature Switzerland AG part of Springer Nature 2021
}

\begin{abstract}
Coronavirus Disease 2019 (COVID-19) has been a global health crisis since it was first identified in December 2019. In addition to fever, cough, headache, and shortness of breath, an intense increase in immune response-based inflammation has been the hallmark of Severe Acute Respiratory Syndrome Coronavirus (SARS-CoV-2) virus infection. This narrative review summarizes and critiques pathophysiology of COVID-19 and its plausible effects on drug metabolism and disposition. The release of inflammatory cytokines (e.g., interleukins, tumor necrosis factor $\alpha$ ), also known as 'cytokine storm', leads to altered molecular pathophysiology and eventually organ damage in the lung, heart, and liver. The laboratory values for various liver function tests (e.g., alanine aminotransferase, aspartate aminotransferase, total bilirubin, albumin) have indicated potential hepatocellular injury in COVID-19 patients. Since the liver is the powerhouse of protein synthesis and the primary site of cytochrome P450 (CYP)-mediated drug metabolism, even a minor change in the liver function status has the potential to affect the hepatic clearance of xenobiotics. It has now been well established that extreme increases in cytokine levels are common in COVID-19 patients, and previous studies with patients infected with non-SARS-CoV-2 virus have shown that CYP enzymes can be suppressed by an infection-related cytokine increase and inflammation. Alongside the investigational COVID-19 drugs, the patients may also be on therapeutics for comorbidities; especially epidemiological studies have indicated that individuals with hypertension, hyperglycemia, and obesity are more vulnerable to COVID-19 than the average population. This complicates the drug-disease interaction profile of the patients as both the investigational drugs (e.g., remdesivir, dexamethasone) and the agents for comorbidities can be affected by compromised CYP-mediated hepatic metabolism. Overall, it is imperative that healthcare professionals pay attention to the COVID-19 and CYP-driven drug metabolism interactions with the goal to adjust the dose or discontinue the affected drugs as appropriate.
\end{abstract}

\section{Key Points}

Inflammation and very high cytokine levels are common in COVID-19 patients.

Inflammatory cytokines are known to contribute to the hepatic dysfunction and suppression of cytochrome P450 (CYP) enzymes.

COVID-19 patients may experience significantly lower hepatic drug clearance due to suppression of CYP-mediated drug metabolism by inflammatory proteins such as interleukins and tumor necrosis factor $\alpha$.

Subrata Deb

sdeb@alumni.ubc.ca

1 Department of Pharmaceutical Sciences, College of Pharmacy, Larkin University, Miami, FL 33169, USA

\section{Introduction}

As of October 14, 2020, the World Health Organization (WHO) has reported 37,888,384 cases of Coronavirus Disease 2019 (COVID-19) and 1,081,868 deaths worldwide [1]. In March 2020, WHO declared COVID-19 as a pandemic [2]. The United States (7,728,436 total cases, 213,626 deaths) has been the epicenter of the disease throughout the pandemic, but several countries in Europe and Asia have also significantly contributed with around 300,000 new cases and thousands of deaths reported every day [1]. WHO's risk assessment of COVID-19 continues to be very high with intense efforts to develop a vaccine ongoing [2]. The Severe Acute Respiratory Syndrome Coronavirus (SARS-CoV-2) is the causative organism responsible for this large-scale pandemic in modern times. SARS-CoV-2 is a novel zoonotic virus that emerged in Wuhan, China, in December 2019 [3]. It was identified in a group of patients who had pneumonia without any known clinical cause [4]. SARS-CoV-2 is in 
the family Coronaviridae, which comprises positive sense single-stranded RNA viruses. The acronym was coined by the International Committee on Taxonomy of Viruses because SARS-CoV-2 is the sister virus of Severe Respiratory Syndrome Coronavirus (SARS-CoV), which caused Severe Acute Respiratory Syndrome (SARS) in 2002 and Middle East Respiratory Syndrome (MERS) in 2012 [5].

Although how the disease first originated in humans is still debatable, current literature points toward bats as the reservoir of the infection as the virus that infects humans is approximately $96 \%$ genetically identical to a coronavirus in bats [6]. However, because apparently the original outbreak started in a 'wet market' in Wuhan, China, it seems unlikely that a bat could have directly infected humans there. Other hypotheses include involvement of an intermediary such as a bat or a pangolin that could have carried the virus to humans [6]. During the first 6 months of the pandemic, the understanding of the mode of transmission between humans underwent some evolution; however, now it is widely accepted that respiratory droplets and direct contact are the main routes of relaying COVID-19. The virus was also detected in the feces of infected patients, which opens up the possibility of fecal-to-oral transmission [6]. There is still the possibility of aerosolized transmission if the infected patient is in close proximity for a long time in a closed environment $[2,6]$. The angiotensin-converting enzyme 2 (ACE2) receptor of the oronasopharyngeal tract in the upper respiratory tract is believed to be the method of uptake of the virus in human hosts. These ACE2 receptors are abundantly expressed in the epithelial cells of the lungs and are also in the digestive tract, which correlates to the most common forms of transmission [6].

Due to the nascent nature of the disease, the scientific community worked on COVID-19 and its related areas in 2020. Despite the herculean research efforts, there is a knowledge gap in understanding the effects of pathophysiology of COVID-19 on hepatic functions, drug metabolism, and pharmacokinetics in SARS-CoV-2 infected patients. Considering the multi-organ targets of SARS-CoV-2, it is critical to appreciate the drug metabolism status and pharmacokinetics of the medications used to treat COVID-19 and to manage the pre-existing conditions. Especially, it has been established that individuals with certain conditions (e.g., hypertension, diabetes, hyperlipidemia) are more susceptible to the infection than the general population [4, 7], which suggests that hepatic drug metabolism is essential to minimize drug-related toxicity during polypharmacy in COVID-19 patients. In this narrative review, we have examined and compared the literature on COVID-19 pathophysiology (e.g., cytokines, inflammation, liver function), examples of infection/inflammation-mediated drug disposition in non-COVID-19 conditions (e.g., drug metabolizing enzyme regulation, drug metabolism), and their plausible effects on the pharmacokinetics of COVID-19 drugs and on the agents that are used to manage comorbidities.

\subsection{Literature Search Strategy}

For the purpose of this narrative review, the PubMed, Medline, and Google Scholar databases were searched for articles up to October 12, 2020. Original research, case studies, FDA package inserts, and review articles were included in the study. Conference abstracts and unpublished e-prints were excluded from this work. Combinations of the following keywords were used to conduct the literature search: "COVID-19", "coronavirus disease 2019", "SARS-CoV-2", "severe acute respiratory syndrome coronavirus 2", "2019nCOV", "2019 novel coronavirus", "coronavirus", "comorbidity", "drug metabolism", "cytochrome P450", "pharmacokinetics", "inflammation" and "cytokines". The literature search and assessment of articles were independently carried out by the authors and then reconciled before analyzing the findings. The current study was restricted to articles that were published in English language and that reported work on humans or in vitro models of human origin.

\section{Pathogenesis and Clinical Presentations of COVID-19}

The clinical presentation of COVID-19 is variable but initial symptoms that most patients have are fever, cough, headache, and shortness of breath [8]. Some patients have tested positive while being completely asymptomatic, which is concerning when dealing with the transmission of the disease. Typically, the observable symptoms start appearing after the 4th day of infection, and the inflammatory responses are more severe around the 10th day. However, it appears that infected individuals are most contagious right before they start showing any easily identifiable symptoms such as fever, cough, and breathing issues [4, 8]. The symptoms and complications of COVID-19 patients significantly differ between home-quarantined and hospitalized patients with intensive care unit (ICU) patients progressively demonstrating worsening systemic conditions [7]. During viral infection, especially from the coronavirus family, after the initial phase, immune response-based inflammation is a hallmark of the disease. Subsequently, inflammation becomes the precursor to organ damage, but sometimes molecular pathological changes may occur even if the organs are mildly affected [3]. As the level of cytokines builds at an incredible pace during the immune response to the infection, patients can experience the 'cytokine storm', which ultimately may lead to organ failure and perhaps septic shock through several mechanisms $[9,10]$. Patients with comorbidities such as diabetes, hypertension, and obesity contracted the disease 
at a much higher rate and developed more severe disease than usually healthy individuals [4]. Age is another major factor determining the severity and mortality of COVID-19 patients [8].

The lungs are one of the most highly perfused organs because of their role in oxygen exchange. Once COVID-19 enters the lungs through ACE2 receptors, it can be transported anywhere in the body through the blood as well organ uptake through ubiquitously expressed ACE2 receptors. The virus can then enter other organs that express ACE2 receptors, which are present in most of the organs in the body including the liver and small intestines [11]. In addition to the lungs, the cardiovascular, hepatic, and nervous systems are commonly coinfected by SARS-CoV-2 [5, 10]. Acute respiratory distress syndrome (ARDS) is the most common complication of the disease and usually requires ventilation for severely ill patients. At the time of preparing this manuscript, the parental dosage forms of the common medications (e.g., dexmedetomidine, fentanyl, lorazepam, midazolam, and propofol) used for sedation prior to intubation were on the FDA drug shortage list [12]. Using optimum sedation and analgesia in the patients is the only ethical and safe way to carry out intubation before a ventilator can be used [13].

\subsection{Laboratory Parameters of COVID-19 Patients}

The abnormal hematological and biochemical laboratory parameters significantly differed between healthy and mildly and severely affected patients [3]. The common out-of-range laboratory values include low albumin, lymphocyte, and platelet levels and increased serum ferritin, procalcitonin, C-reactive protein (CRP), lactate dehydrogenase (LDH), white blood cell count, alanine aminotransferase (ALT), aspartate aminotransferase (AST), cardiac troponin I, serum creatinine, and erythrocyte sedimentation rate (ESR) levels and a series of inflammatory markers [3]. It is exceedingly common to see bilateral opacities, which is a sign of ARDS in patients who have undergone $x$-ray imaging $[3,14]$. In a meta-analysis, $87.5 \%$ of patients had bilateral involvement showing that the infection spreads quickly in the lungs [14]. The LDH levels can describe a patient who is having extensive tissue damage. Decreased albumin levels and increased inflammation-related markers and elevated liver enzyme levels suggest that the inflammation likely affects the liver early in the disease timeline. Similarly, increased troponin levels along with the immunogenic response point toward cardiac injury in those patients [10].

\subsection{Increased Inflammation in COVID-19 Patients}

A strong immunological response in the defense against the SARS-CoV-2 infection leading to inflammation has been reported as a hallmark in COVID-19 patients. The neutrophil-to-lymphocyte ratio, CRP, ESR, ferritin, and procalcitonin levels along with cytokines are the typical markers of infection-related inflammation. In a meta-analysis, $58.3 \%$ of patients had a high serum CRP ( $>3 \mathrm{mg} / \mathrm{l})$ and $41.8 \%$ of patients had a high ESR, indicating a heightened level of inflammation [3]. Table 1 depicts the CRP and LDH levels in representative clinical reports on COVID-19 patients. Death due to precipitation of inflammation leading to organ dysfunction is potentially one of the most common scenarios in severe COVID-19 patients $[6,8,15]$. The inflammatory cascade is different for every organ but several aspects including the initiation are similar. During the first few days of the virus contraction, the body recognizes the invasion by the pathogen, which drives the local release of inflammatory cytokines and chemokines, most commonly, interleukins (ILs), tumor necrosis factor $\alpha$ (TNF $\alpha$ ), interferon gamma (IFN $\gamma$ ), and monocyte chemoattractant protein 1 (MCP1), to restrict the infection to limited compartments of the body [16]. Subsequently, at the peak of the viral titer, systemic inflammation appears as a 'cytokine storm' in COVID-19 patients where intense production and release of cytokines and other immunogenic proteins are observed. The examples of increased inflammatory markers in COVID-19 patients are shown in Table 2. The inflammatory mediators along with the virus cause cellular injury leading to scar tissue or fibrosis formation, loss of function or ischemia, and eventually tumor necrosis [16]. High LDH is an early sign of cellular injury followed by subsequent deleterious effects of SARS-CoV-2 infection [17]. The most common organ failures reported are of the lungs, heart, and kidneys, in that order. Inflammation in the lungs is detected by computerized tomography (CT) or chest x-ray imaging. A systematic review showed that $>87 \%$ of patients with a CT scan had bilateral involvement. The same review showed $78.8 \%$ of patients had multilobar involvement [14]. These observations show that the virus quickly spreads in the lungs possibly because of the many ACE2 receptors in that area and also due to the fact that lung is the first major organ after the virus enters into the human body through the oronasopharyngeal route [6]. To cause damage to the liver, which is the focus of this review, the inflammation caused by COVID-19 has to be systemic or by direct infection of the liver through the hepatic ACE2 receptors.

Several studies have convincingly reported that patients with severe cases of SARS-CoV-2 have elevated serum levels of IL-1 $\beta$, IL-2R, IL-6, IL-8, IL-10, IL-12, IL-18, IFN $\gamma$, MCP1, and TNF $\alpha$ [9, 18-24]. The systemic inflammation triggered by the 'cytokine storm' is essentially the roadway to the molecular pathophysiological cascades and eventually organ failure. Among the cytokines, IL-1, IL-6, TNF $\alpha$, and IFN $\gamma$ have been widely analyzed [17]. The levels of IL-6 were more commonly monitored in the studies that reported cytokine levels in COVID-19 patients because there 


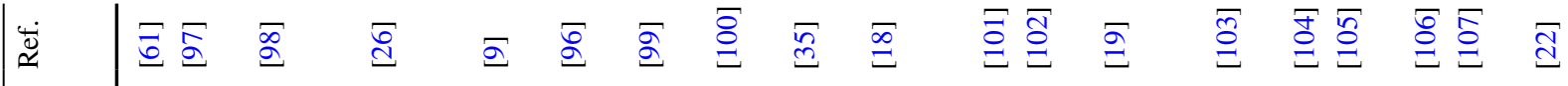

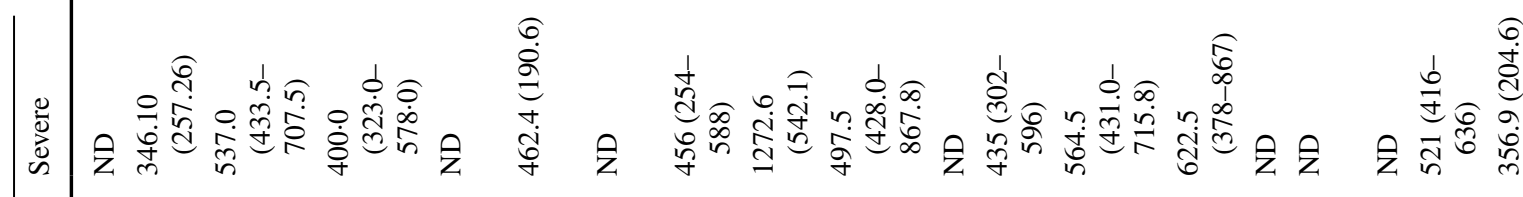

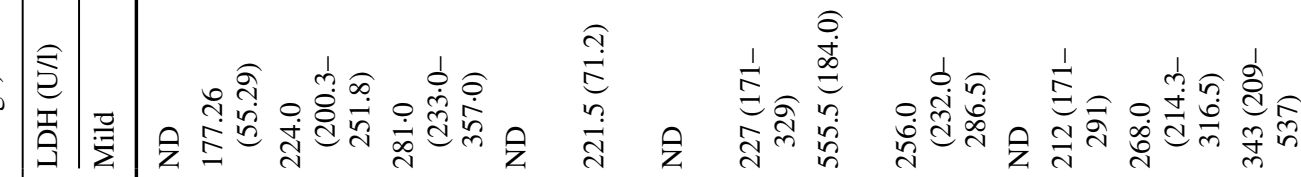

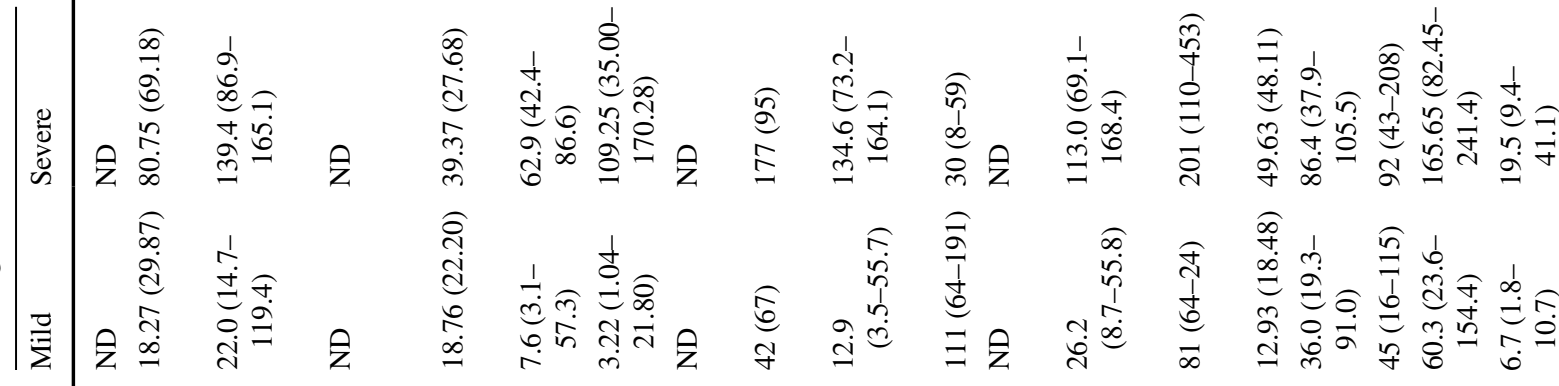

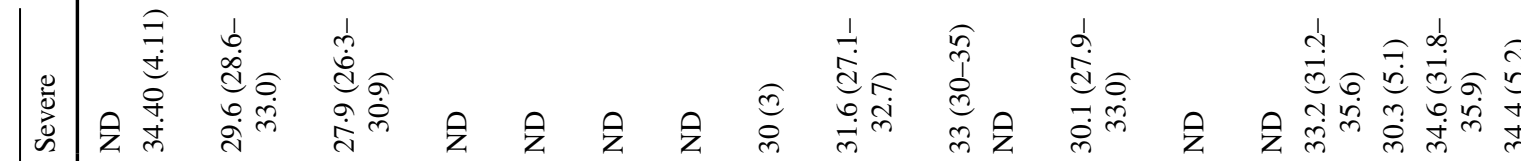

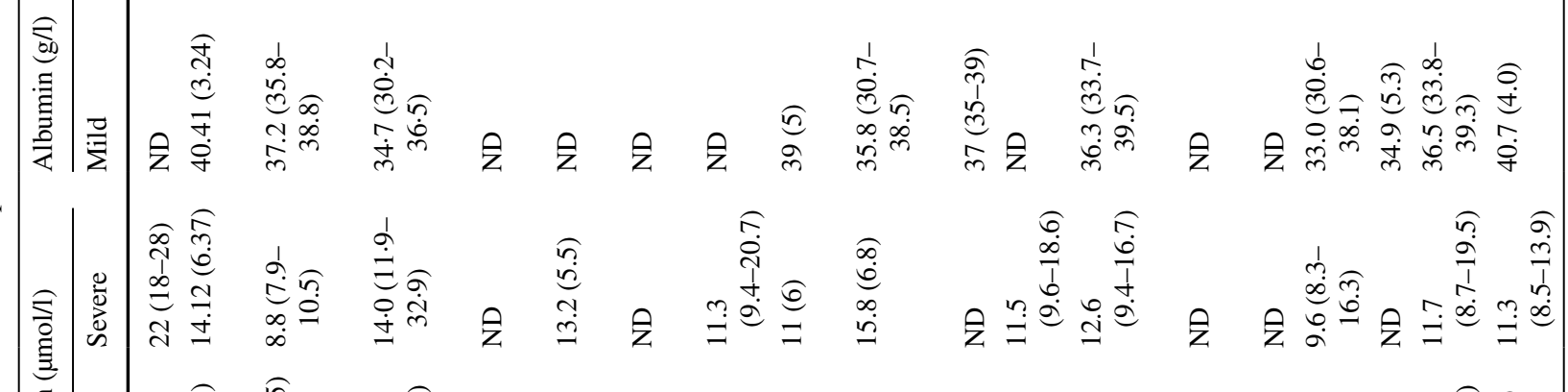

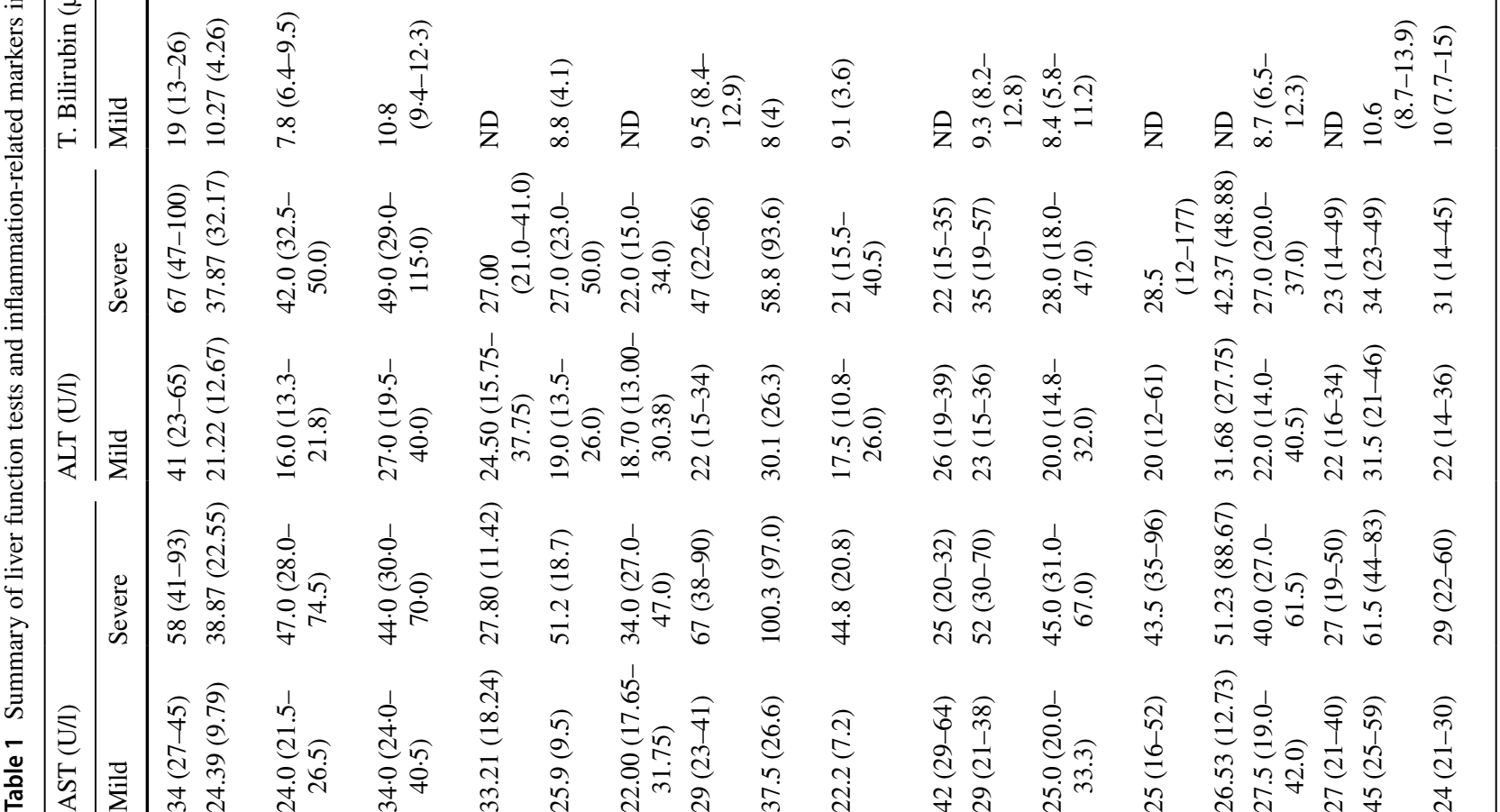




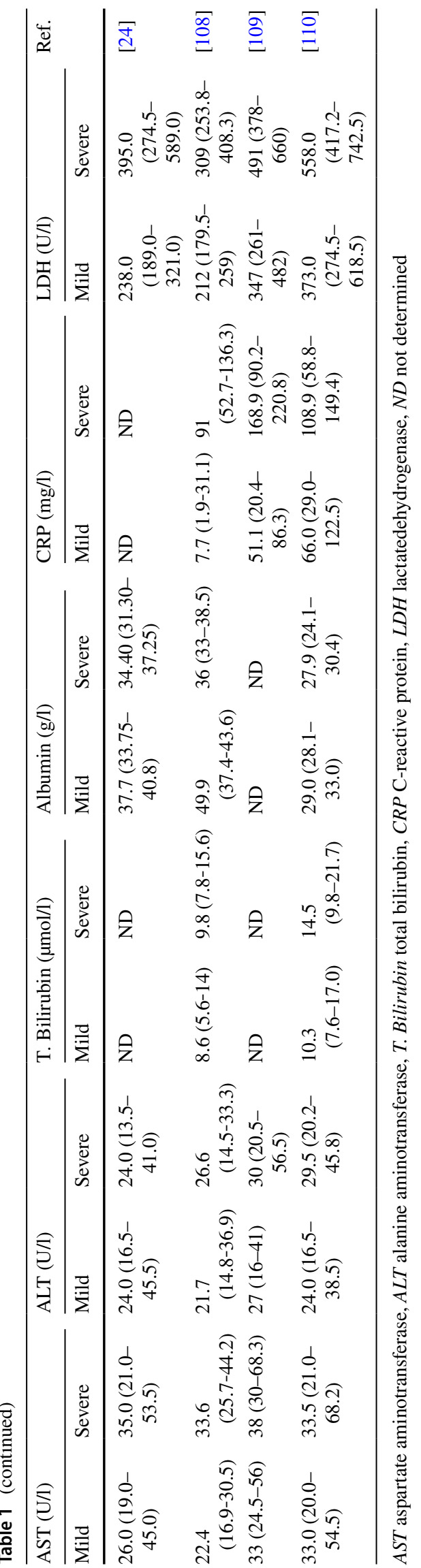

was a very close positive relationship with IL-6 and severity of the illness. Patients with severe cases of SARS-CoV-2 have two- to five-fold elevated IL-6 concentrations during different stages of infection [25]. The increased IL-6 level ( $>24.3 \mathrm{pg} / \mathrm{ml}$ ) has shown a strong correlation with severe symptoms of COVID-19 [25]. The presence of a higher level of IL-6 (> $24.3 \mathrm{pg} / \mathrm{ml})$ could detect severe cases with a sensitivity of $73.3 \%$ and a specificity of $89.3 \%$ [9]. Other studies have linked the 'cytokine storm' phenomenon with patients needing to go to the ICU and use of ventilators [26, 27]. Bangash et al. demonstrated an indirect link between IL- 6 and mortality where COVID-19 patients in the ICU with higher IL-6 levels had a 44\% mortality rate [28]. Similarly, a direct link between higher levels of IL-6, ferritin, and mortality was also shown by Mehta et al. [15]. Interestingly, IL-6 was shown to grow steadily in most patients from the moment of infection until death or cure [29]. The knowledge of cytokine levels in COVID-19 patients facilitates understanding of the inflammatory status and eventually can predict their potential effects on drug metabolizing enzyme expression, drug metabolism, and pharmacokinetics. In subsequent sections, we have examined the cytokine increase in non-SARS-CoV-2 infection/inflammation, their effects on drug metabolism and pharmacokinetics, and finally how these may be reflected in COVID-19 patients. It has been reported that the cytokine levels significantly differ between mild and severe COVID-19 patients [9, 18-24], which may also point toward the fact that, depending on the disease severity, inflammation and drug disposition or drug-related toxicity will likely differ between individuals (Fig. 1).

\subsection{Liver Function Status in COVID-19 Patients}

During SARS-CoV-2 infection, the liver is one of the major organs targeted by the virus. Since the ACE2 receptor is expressed in the liver, there could be a dual effect of direct viral attack and systemic inflammation and its related proinflammatory immunogenic proteins targeting hepatic machineries [17]. Similar to the previous coronavirus infections, in COVID-19-related patients, different extents of elevated ALT, AST, alkaline phosphatase (ALP), gamma glutamyl transpeptidase (GGT), bilirubin, and albumin levels have been indicated in hepatocellular injury [17]. Typically, at least two times the upper normal level (ULN) of ALT (or AST) draws the attention of the healthcare team [17, 30, 31]; however, it is extremely important to recognize that the context is critical. Although ALT is a reliable marker of abnormal liver health, the ratio of AST to ALT $(>1)$ points toward progressive fibrosis or cirrhosis [30-32]. The markers for liver functions were commonly elevated but studies vary on the percentage of the increase. While looking at the markers for hepatocellular injury, two aspects should be analyzed, namely, the higher range of levels attained and 


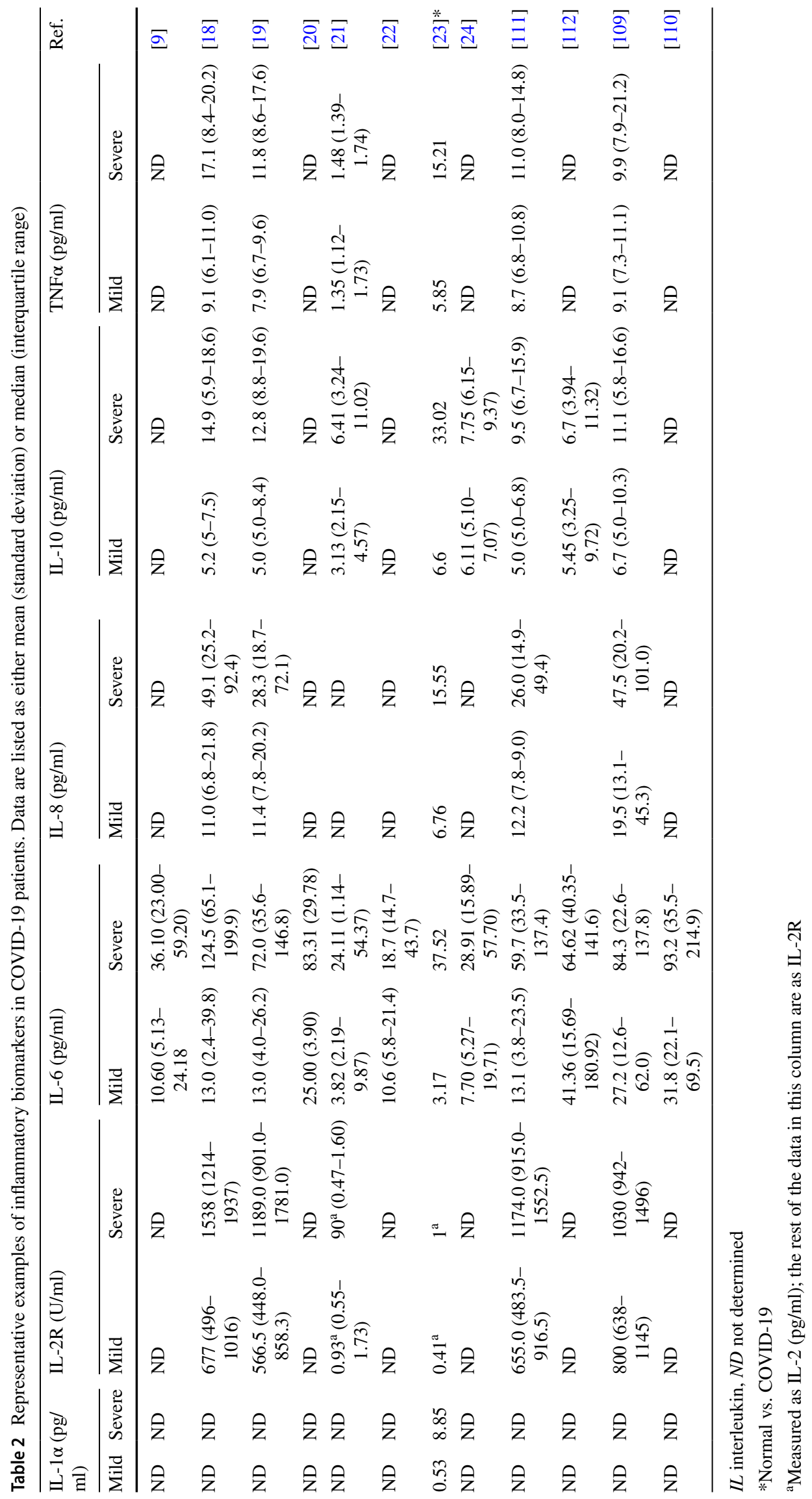




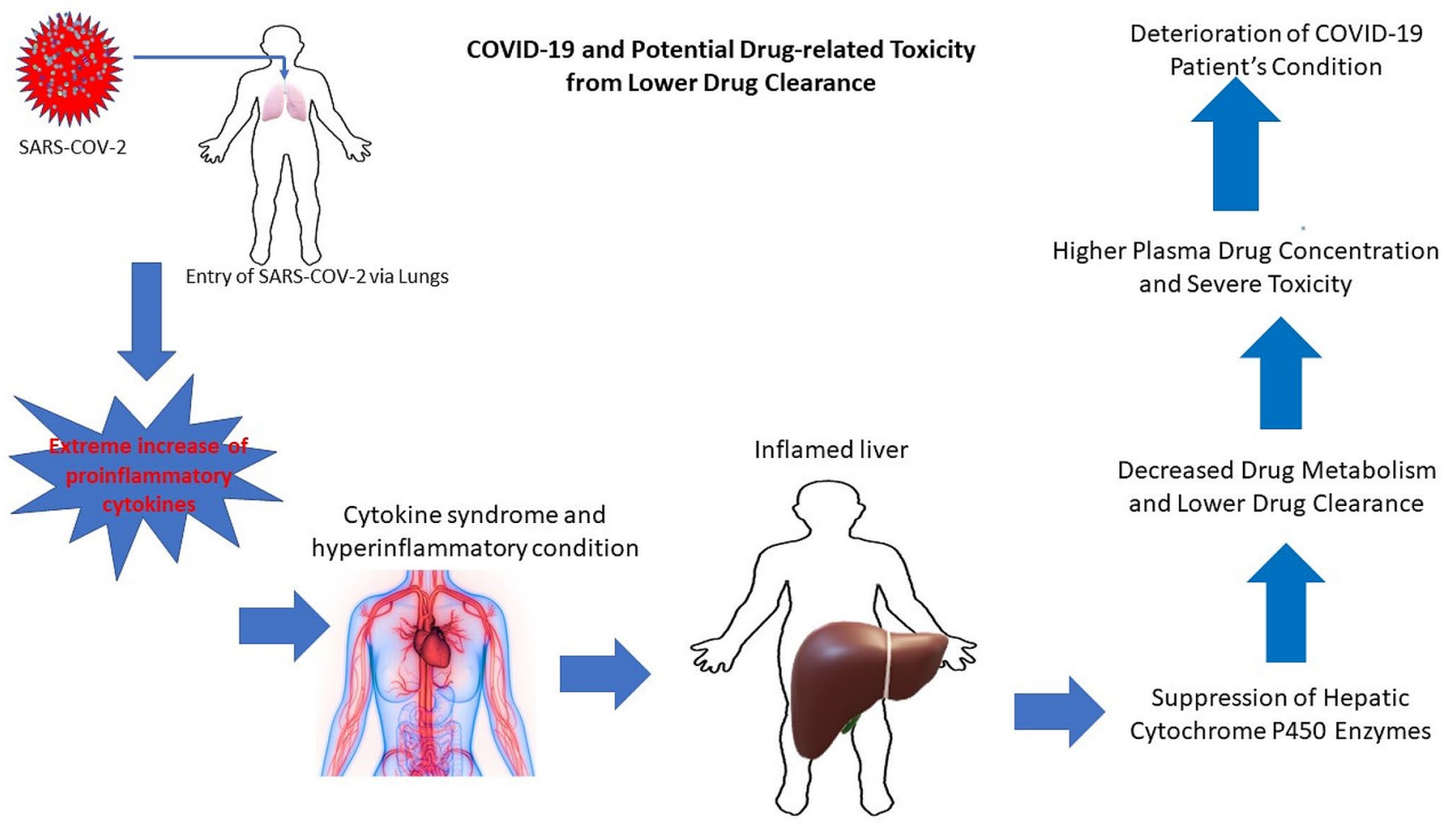

Fig. 1 Potential effects of COVID-19-related inflammation on hepatic cytochrome P450 regulation, drug metabolism, and clearance

the percentage of COVID-19 patients with abnormal liver markers. Analyses of results from COVID-19 patient cohorts indicate that typically the liver function markers were elevated up to five-fold compared with the ULN, in some cases with extraordinarily high numbers [17]. For example, ALT was elevated up to 7590 U/l in COVID-19 patients [27]. Approximately $30 \%$ of the COVID-19 patients in different studies have AST and ALT values above the normal range (> $40 \mathrm{U} / 1$ ). One study showed that $50.7 \%$ of patients had high ALT and $18.2 \%$ of patients had high AST levels [27]. Another study showed similar results with $45 \%$ of patients showing high AST and $21 \%$ of patients showing elevated ALT levels with a strong correlation between elevated liver enzymes and severity of the disease [27]. In deceased patients, there is about a $78 \%$ prevalence of abnormal liver marker levels [27]. It is vital to note that the percentage of patients with abnormal results was considered with a stratification of $<$ or $>40$ IU/l for AST or ALT. However, in recent years the major clinical guidelines have convincingly highlighted that the numbers for ULN should be $<$ $40 \mathrm{IU} / \mathrm{l}$, for example, for hepatoprotective purposes the ALT ULN for men should be 30 and for females 19 IU/1 [33]. If this yardstick is taken into account, most of the COVID-19 patients where liver tests are reported will have elevated levels. Previously, researchers and clinicians have opined that it is extremely important to establish the cause and effect correlation of ULN for liver enzymes and liver health [28].
A summary of representative studies reporting liver function tests in COVID-19 patients is listed in Table 1. Since the liver is the powerhouse of protein synthesis, even with a minor change in the metabolic profile due to COVID-19, there will be a significant impact on intrinsic hepatocyte functions such as endogenous substance biosynthesis and xenobiotic biotransformation through altered enzymatic expression [34]. While the decreased albumin and elevated liver enzyme levels suggest that the inflammation is affecting the liver [35], the hepatocellular injury can have a wide range of effects on the metabolism of endogenous substances and xenobiotics including altered physiological, therapeutic, and toxic outcomes.

\section{Effect of Inflammation on Cytochrome P450 Enzyme Expression and Drug Metabolism}

Drug metabolizing enzymes (DME) are critical for the biotransformation and eventually pharmacokinetics of most medications. Metabolism is the process of changing the lipophilic chemical structure of the drug to make it more hydrophilic and therefore easier to excrete. In most cases of drug metabolism, it will inactivate the medication, whereas in a small percentage of drugs (e.g., clopidogrel) bioactivation 
is the primary outcome of the metabolism. A third class of drugs is active to begin with but also have active metabolites following metabolism (e.g., morphine) [36]. Cytochrome P450 (CYP) enzymes are a superfamily of phase I DMEs that are key players in the metabolism of therapeutic small molecule drugs, environmental toxicants, and health supplements [37]. CYP enzymes commonly catalyze a wide range of oxidative reactions including hydroxylation, which makes the medications more water-soluble and enable the kidneys to excrete them. Currently, the superfamily has 57 CYP isoforms, which are classified into 18 families and 43 subfamilies. The enzymes from families 1-4 are primarily involved in the xenobiotic metabolism whereas enzymes that belong to family 5 and higher contribute to the biosynthesis and elimination of endogenous hormones, vitamins, and other physiological substances [37]. CYP3A4 is the most critical metabolizing enzyme for possible interactions because $>60 \%$ of medications are metabolized by CYP3A4. Other major DMEs include CYP1A2, CYP2B6, CYP2C9, CYP2C19, and CYP2D6. Similarly, phase II DMEs (e.g., UGTs, SULTs) are also key components in the hepatic metabolism and elimination of xenobiotics [37]. This discussion will include the regulation of xenobiotic metabolizing CYP enzyme expression and function, which are frequently induced or inhibited by endogenous and exogenous factors. Altered CYP expression and function due to inflammation lead to an abnormal drug plasma profile and elimination, which drives the adverse effects and drug toxicity-related fatal outcomes [37].

\subsection{Impact of Cytokine and Other Inflammatory Proteins on CYP Regulation}

Immunogenic proteins, such as IL-1, IL-6, IFN $\gamma$, and TNF $\alpha$, can suppress the CYP enzymes during viral infection [38, 39], but no data are available yet on CYP regulation during SARS-CoV-2 infection. Nevertheless, the CYP regulation profile controlled by cytokines and other inflammatory proteins has been extensively studied in the past. Also, the effects of non-SARS-CoV-2 viral infections and other inflammatory diseases on CYP regulation can be used to draw a plausible picture in COVID-19 patients. In vitro study with hepatocytes has shown that IL-6 decreased (> $40 \%$ ) the expression of major CYP isozymes [39]. A differential IL-6-mediated decrease in expression was observed for CYP1A2, CYP2B6, CYP2C8, CYP2C9, CYP2C19, and CYP3A4 isozymes [39]. CYP2B6 and CYP3A4 have been reported to be the most impacted isoforms in inflammation-related CYP downregulation [39]. Table 3 presents the effects of inflammatory cytokines, which are commonly detectable in COVID-19 patients, on CYP expression. The effects of inflammatory cytokines on CYP expression are summarized in Table 3.

A study on human hepatocytes demonstrated that IL6-mediated downregulation of CYP enzymes is a concentration-dependent phenomenon. Following treatment with $1 \mathrm{ng} / \mathrm{ml}$ IL-6 for $24 \mathrm{~h}$, CYP3A4 levels were decreased by $47 \%$ of the normal levels [40]. Compared to CYP2B6 and CYP3A4, the suppression of CYP2C9 expression is more resilient as it required $5 \mathrm{ng} / \mathrm{ml}$ IL-6 to lower the expression

Table 3 Effect of inflammatory cytokines on cytochrome P450 (CYP) enzymes (either mRNA or protein) expression

\begin{tabular}{|c|c|c|c|c|c|c|c|c|}
\hline Marker & CYP1A2 & CYP2B6 & CYP2C9 & СYP2C19 & CYP2D6 & CYP3A4 & Model & Ref. \\
\hline IL-1 $\beta$ & ND & ND & ND & ND & ND & $\downarrow \downarrow \downarrow$ & Human hepatoma cells & [87] \\
\hline IL-6 & ND & ND & ND & ND & ND & $\downarrow \downarrow \downarrow$ & & \\
\hline TNF $\alpha$ & ND & ND & ND & ND & ND & $\downarrow \downarrow \downarrow$ & & \\
\hline $\mathrm{IL}-1 \beta$ & ND & ND & ND & ND & ND & $\downarrow \downarrow \downarrow$ & Human hepatocytes & [45] \\
\hline IL-1 $\beta$ & $\leftrightarrow$ & $\leftrightarrow$ & $\leftrightarrow$ & ND & ND & $\leftrightarrow$ & Human hepatocytes & [113] \\
\hline IL-6 & $\leftrightarrow$ & $\downarrow \downarrow \downarrow$ & $\downarrow$ & ND & ND & $\downarrow \downarrow \downarrow$ & & \\
\hline IL-6 & $\downarrow \downarrow$ & $\downarrow \downarrow \downarrow$ & ND & ND & ND & $\downarrow \downarrow \downarrow$ & HepaRG cells & [114] \\
\hline IL-1 & $\downarrow \downarrow \downarrow$ & ND & ND & ND & ND & $\downarrow \downarrow \downarrow$ & Human hepatocytes & [115] \\
\hline IL-6 & $\downarrow$ & ND & ND & ND & ND & $\downarrow \downarrow$ & & \\
\hline $\mathrm{TNF} \alpha$ & $\downarrow \downarrow$ & ND & ND & ND & ND & $\downarrow \downarrow$ & & \\
\hline IL-1 & ND & $\leftrightarrow$ & $\leftrightarrow$ & $\leftrightarrow$ & ND & $\downarrow \downarrow \downarrow$ & Human hepatocytes & [42] \\
\hline IL-6 & ND & $\downarrow \downarrow \downarrow$ & $\downarrow \downarrow$ & $\downarrow \downarrow$ & ND & $\downarrow \downarrow \downarrow$ & & \\
\hline $\mathrm{TNF} \alpha$ & ND & $\leftrightarrow$ & $\leftrightarrow$ & $\leftrightarrow$ & ND & ND & & \\
\hline IL-2 & ND & $\downarrow \downarrow$ & ND & ND & ND & $\downarrow \downarrow$ & Peripheral blood mononuclear cells & [116] \\
\hline IL-6 & ND & $\downarrow$ & ND & ND & ND & $\downarrow$ & & \\
\hline IL-10 & ND & $\leftrightarrow$ & ND & ND & ND & $\leftrightarrow$ & & \\
\hline IL-6 & $\downarrow \downarrow \downarrow$ & $\downarrow \downarrow \downarrow$ & $\downarrow \downarrow \downarrow$ & $\downarrow \downarrow$ & $\mathrm{ND}$ & $\downarrow \downarrow \downarrow$ & Cryopreserved human hepatocytes & [40] \\
\hline
\end{tabular}

$\downarrow$ indicates up to $25 \%$ decrease, $\downarrow \downarrow$ indicates $26-50 \%$ decrease, $\downarrow \downarrow \downarrow$ indicates $>50 \%$ decrease, $\leftrightarrow$ indicates no change, CYP cytochrome P450, $I L$ interleukin, $N D$ not determined 
by $65 \%$ [40]. The average $\mathrm{EC}_{50}$ values for IL-6-driven downregulation of CYP3A4, CYP2B6, and CYP2C9 are 1.2, 1.9, and $3.6 \mathrm{ng} / \mathrm{ml}$, respectively [40]. Interindividual variability was observed in the extent of CYP downregulation by IL-6 exposure [41]. The role of IL-6 in producing inflammationmediated CYP downregulation was explained through the use of turpentine, a chemical used to induce inflammation, in an IL-6-deficient mouse model. Turpentine was unable to cause inflammation and CYP downregulation in IL-6-deficient mice in contrast to the wild-type IL-6 mice in vivo [42]. In addition, the authors measured the effects of other inflammatory cytokines which are frequently present in COVID-19 patients. TNF $\alpha$, IFN $\gamma$, TGF, and IL-1 significantly downregulated CYP3A4 expression [43]. It is unknown whether in a 'cytokine storm', where multiple cytokines are intensely elevated, the effects of cytokines on CYP enzymes would be additive or synergistic. Regardless, it seems that drug metabolism can be greatly affected by the type of inflammation that COVID-19 patients usually experience.

The mechanism of inflammation-related downregulation can be highly diverse. Aryl hydrocarbon receptors (AhR), constitutive androstane receptors (CAR), and the pregnane $\mathrm{X}$ receptors (PXR) are the major regulators of the CYP1, CYP2, and CYP3 family enzymes, respectively [44]. Suppression of AhR, CAR, and PXR followed by transcriptional downregulation of CYP mRNA and protein expression is the most ubiquitous pathway of cytokine and other inflammation-mediated effects [37, 42, 43]. For example, IL-1 $\beta$ decreases CAR expression [43]. The role of IL- $1 \beta$ in the suppression of CYP enzymes was explained by partial reversal of downregulation by gevokizumab, an anti-IL-1b monoclonal antibody [45]. Another mechanism of inflammation-driven CYP3A4 suppression involves C/EBP $\beta$ protein. The mice triggered by inflammatory mediators (e.g., IL- $1 \beta$, IL-6, TNF $\alpha$, IFNy) produced a truncated version of C/EBP $\beta$, which antagonized the activity of the full version leading to inhibition of CYP3A4 [42]. In addition, oxidative stress is a common phenomenon during infection and inflammation, which is known to lower CYP expression via free radical mechanisms [46]. This was rationalized through attenuation of inflammation-related downregulation via administration of a vitamin $\mathrm{E}$ analog, a known free radical scavenger [42].

\subsection{Drug Metabolism and Disposition During Infection and Inflammation}

The primary function of CYP enzymes is to facilitate drug elimination through an oxidative reaction. Thus, viral infection- and cytokine-related downregulation of CYP expression has a direct impact on the drug disposition and pharmacokinetics in humans. The effects of several viruses, e.g., hepatitis A, influenza A and B, adenovirus, herpes simplex, and human immunodeficiency virus (HIV), on CYP-dependent drug metabolism have been studied [47]. Reports of the effect of SARS-CoV-2 on drug-metabolizing enzymes or the metabolism itself are scarce but the pharmacokinetics of different COVID-19 investigational drugs have recently become available to a limited extent. The increased plasma levels and decreased elimination of cyclosporine, a CYP3A4 substrate, were driven by higher IL-6 levels in bone marrow transplant patients $[42,48]$. Similar disease-drug interactions were confirmed for simvastatin and cyclosporine through physiologically based pharmacokinetic simulations [49]. Metabolism of midazolam, a CYP3A probe substrate, was decreased $12 \mathrm{~h}$ after inducing inflammatory conditions with glucose-6-phosphate-isomerase as measured by increased serum IL- 6 and TNF $\alpha$ levels and suppression of CYP3A mRNA [50]. CYP1A2-mediated hepatic clearance of theophylline is decreased by adenovirus or influenza virus [46]. Similarly, inflammatory effects decreased the metabolism of protease inhibitors by CYP3A4 in HIV patients [51]. Analyses of infection- and inflammation-mediated suppression of drug clearance and other pharmacokinetic parameters clearly highlight that immunogenic proteins like cytokines can directly contribute to the interindividual variability of the therapeutic and toxic outcomes of pharmacological interventions.

\subsection{Pharmacokinetics of COVID-19 Drugs in Infected Patients}

The treatment regimens of COVID-19 patients could be complex for several reasons including targeting of diverse pathophysiology and symptoms. The pharmacokinetic profile of investigational drugs in COVID-19 patients primarily involves antiviral and antiprotozoal agents. Remdesivir, which is the only US FDA-approved drug for COVID19, has very limited reports of disposition in COVID-19 patients. Sorgel et al. reported that the area under the concentration-time curve, maximum concentration, clearance, and volume of distribution of the parent remdesivir differ by 2.5 - to 4-fold between healthy volunteers and COVID19 patients with renal impairment [52]. The package insert of the drug indicates that only $10 \%$ of the metabolism is mediated by CYP enzymes [53], so it is unclear if the higher PK values are results of renal impairment, infection-related downregulation of the metabolizing enzymes, or perhaps a combination of both. Lopinavir/ritonavir and darunavir are the anti-retroviral medications that are approved to treat HIV and are now being repurposed for SARS-CoV-2 [54-56]. As a result, recent $\mathrm{PK}$ reports on these antiviral drugs compare their median peak-trough levels in COVID-19 patients with previous studies with HIV-infected individuals. There was a significant difference in plasma lopinavir concentrations between survivor and non-survivor COVID-19 patients. 
The 13 patients of the study had median CRP levels of $>$ 170 U/1 [57]. Another study reported a major difference in the median oral clearance $(\mathrm{CL} / \mathrm{F})$ of darunavir between COVID-19 patients with IL-6 $>18 \mathrm{pg} / \mathrm{ml}$, patients with an IL-6 $<18 \mathrm{pg} / \mathrm{ml}$, and HIV patients not infected with SARSCoV-2 (2.78, 7.24, 9.75 1/h) [54]. However, no significant difference was observed in CL/F between patients with IL-6 $<18$ pg/ml and HIV patients. Comparison between non-stratified COVID-19 patients and HIV patients (IL-6 levels $31.0 \mathrm{pg} / \mathrm{ml}$ vs. $2.0 \mathrm{pg} / \mathrm{ml}$ ) exhibited lower darunavir CL/F in the SARS-CoV-2-infected patients. IL-6 was the only factor that was significantly correlated with $\mathrm{CL} / \mathrm{F}$. Other factors that were tested included age, body weight, BSA, serum creatinine, ALT, and AST levels, and concomitant hydroxychloroquine administration [54]. Similarly, plasma lopinavir concentrations were six times higher in COVID-19 patients (median CRP $186 \mathrm{mg} / \mathrm{l}$ ) compared to HIV patients [55]. Marzolini et al. described lopinavir and hydroxychloroquine plasma concentrations in COVID-19 patients when given concomitantly [58]. Lopinavir levels were higher in COVID-19 patients compared to the HIV cohort. Patients with higher CRP values ( $>75 \mathrm{mg} / \mathrm{l})$ had a higher lopinavir trough concentration compared to the patients with $\mathrm{CRP}<75 \mathrm{mg} / \mathrm{l}$. Plasma hydroxychloroquine concentrations did not correlate with CRP levels. Age $(<65$ or $>65$ years) had no effect on the lopinavir concentrations when compared between patients with similar CRP value ranges [58]. In several studies, a positive correlation was observed between the lopinavir trough concentration and
CRP values in COVID-19 patients [55, 58, 59]. Interestingly, lopinavir trough levels were lower following administration of tocilizumab, a monoclonal antibody against IL-6 receptor, which suggests that inflammation-related downregulation of drug metabolism and hepatic clearance plays a major role in the disposition of COVID-19 drugs [58]. This validates the concept that a certain CYP enzyme expression is suppressed by inflammatory proteins during an active infection or inflammation [38, 39, 41]. Indeed, lopinavir and darunavir are primarily metabolized by CYP3A4, but the same enzyme has a minor role in hydroxychloroquine metabolism. This suggests that inflammation-mediated downregulation of CYP3A4 could lead to lower metabolism, decreased clearance, and increased plasma concentration of the COVID-19 CYP3A4 substrate drugs. The anti-inflammatory effects of tocilizumab may have the ability to decrease the elevated cytokine levels and plasma drug levels, thus protecting the patients from increased toxicity [58]. The inflammationdriven suppression of the PK phenomenon may be applicable to other drugs administered to manage comorbidities and can potentially complicate the disposition profile of the patients. For example, everolimus, an immunosuppressive drug used in transplant patients, can be affected by lower CYP3A4 activity as well as by CYP3A4 inhibitory effects of anti-viral drugs [60]. A brief summary of the pharmacokinetics of drugs in COVID-19 patients is given in Table 4.

Table 4 Pharmacokinetics of antiviral agents in COVID-19 patients. Except one (darunavir), all the concentrations are indicative of lopinavir levels

\begin{tabular}{|c|c|c|c|c|c|}
\hline Patients & Medication & Concentration & Biomarkers & Observation & Ref. \\
\hline 13 & Lopinavir/ritonavir & Cmax-Cmin 20-30 mg/l & Median CRP > $170 \mathrm{U} / 1$ & $\begin{array}{l}\text { Inflammation was associated with } \\
\text { lower CYP concentration }\end{array}$ & [57] \\
\hline 30 & Darunavir & $\begin{array}{l}\text { CL/F: IL-6 levels > } 18 \text { pg/ml: } 2.78 \\
\text { 1/h ; IL-6 levels < } 18 \text { pg/ml: } 7.24 \\
\text { 1/h (HIV: } 9.75 \text { 1/h) }\end{array}$ & $\begin{array}{l}\text { Median IL-6 } 31.0 \mathrm{pg} / \\
\mathrm{ml}(\mathrm{HIV} 2.0 \mathrm{pg} / \mathrm{ml})\end{array}$ & $\begin{array}{l}\text { IL-6 was the only factor with signifi- } \\
\text { cant association to oral clearance }\end{array}$ & [54] \\
\hline 17 & Lopinavir/ritonavir & $\begin{array}{l}\text { AUC: } 668,788 \mathrm{ng} \cdot \mathrm{h} / \mathrm{ml} \text { (HIV patients: } \\
\text { 113,200 } \mathrm{ng} \cdot \mathrm{h} / \mathrm{ml})\end{array}$ & Median CRP 186 mg/l & $\begin{array}{l}\text { Mechanically ventilated patients; } \\
\text { positive correlation between CRP vs. } \\
\text { lopinavir trough concentration }\end{array}$ & [55] \\
\hline 92 & Lopinavir/ritonavir & $\begin{array}{l}\text { Cmin level: } 26.5 \mu \mathrm{g} / \mathrm{ml} \\
\text { CRP > } 75 \mathrm{mg} / \mathrm{l}: 30.7 \mu \mathrm{g} / \mathrm{ml} \\
\text { CRP < } 75 \mathrm{mg} / \mathrm{l}: 20.9 \mu \mathrm{g} / \mathrm{ml} \\
\text { (HIV patients: } 7.1 \mu \mathrm{g} / \mathrm{ml} \text { ) }\end{array}$ & $\begin{array}{l}\text { Median non-ICU CRP } \\
53 \mathrm{mg} / \mathrm{l} ; \text { ICU CRP } \\
89 \mathrm{mg} / \mathrm{l}\end{array}$ & $\begin{array}{l}\text { Positive correlation between CRP vs. } \\
\text { lopinavir trough concentration; tocili- } \\
\text { zumab lowered trough levels }\end{array}$ & [58] \\
\hline 12 & Lopinavir/ritonavir & $\begin{array}{l}\text { Cmax: } 18,150 \mathrm{ng} / \mathrm{ml} ; \mathrm{Cmin}: 18,000 \mathrm{ng} / \\
\text { ml (HIV: } 5365 \mathrm{ng} / \mathrm{ml})\end{array}$ & Median CRP: $48.9 \mathrm{mg} / \mathrm{l}$ & Hospitalized patients & [117] \\
\hline 8 & Lopinavir/ritonavir & $\begin{array}{l}\text { Cmin: } 13.6 \mu \mathrm{g} / \mathrm{ml} \\
\text { (HIV: } 7.1 \mu \mathrm{g} / \mathrm{ml} \text { ) }\end{array}$ & Mean $38.05 \mathrm{mg} / \mathrm{l}$ & Association of lopinavir Cmin vs. CRP & [59] \\
\hline 21 & Lopinavir/ritonavir & $\begin{array}{l}\text { Cmin: } 15.235 \mu \mathrm{g} / \mathrm{ml} \\
\text { (HIV: } 4.882 \mu \mathrm{g} / \mathrm{ml})\end{array}$ & CRP 77 mg/l & $\begin{array}{l}\text { Concomitant exposure to hydroxychlo- } \\
\text { roquine }\end{array}$ & [118] \\
\hline
\end{tabular}

$A U C$ area under the concentration-time curve, $C \max$ maximum concentration, $C \min$ minimum concentration, $C L / F$ clearance, $C R P$ C-reactive protein, CYP cytochrome $\mathrm{P} 450, I C U$ intensive care unit 


\section{Drug Metabolism and Disposition in COVID-19 Patients}

\subsection{More Than Liver Dysfunction, the Acute Effects on Drug Metabolism Enzyme Expression}

Most of the liver health data from COVID-19 patients have strongly indicated that liver enzyme (e.g., AST, ALT) levels significantly increase, and it is clear that the liver undergoes severe stress during the period of SARS-CoV-2 infection $[17,35,61]$. However, since the acute phase of the disease is relatively short, at this time it is unknown how the liver health of the patients will be once they recover from the infection. Depending on the severity of the inflammationand infection-related hepatic damage, the patient(s) may experience long-term liver abnormalities including necrosis and organ failure $[17,61,62]$. Irrespective of the prognosis of liver dysfunction, due to the elevated cytokine levels, comparable to other viral infections, it is likely that patients will experience acute suppressive effects on CYP expression, reduced drug metabolism, decreased drug elimination, and eventually local and systemic drug toxicity as early as 48-72 $\mathrm{h}$ after active infection [46, 47, 51]. Similar to other viral infections, local and systemic inflammation as well as the 'cytokine storm' during COVID-19 progression will potentially cause downregulation of the major CYP enzymes including CYP3A4, CYP2B6, and CYP2C9 [46, 47, 51]. Since toxic drug concentrations are one of the most common reasons for drug-induced liver injury [63], the abnormal liver parameters during SARS-CoV-2 infection could also be contributed by both the virus-related events and hepatotoxicity from the experimental drugs that are being used to treat COVID-19 or FDA-approved drugs for comorbidities. Interindividual variability in liver abnormalities and inflammation-related downregulation of CYP enzymes are other prominent factors to be considered [64, 65]. Along with the uncertainty about the length of abnormal liver health, patients may also experience different acute responses in CYP expression, which might pose additional challenges to predicting liver health during COVID-19 progression (Fig. 2).

\subsection{Impact of Disease Pathophysiology on Investigational COVID-19 Drug Disposition}

Currently, there is no standard of care medication to treat COVID-19. However, hospitalized patients are typically given a broad array of experimental and approved drugs to manage the conditions. Most of the treatments come from supportive care including acetaminophen for fever and ventilation for dyspnea leading to ARDS [5]. Although there is no FDA-approved treatment for SARS-CoV-2, the repurposed
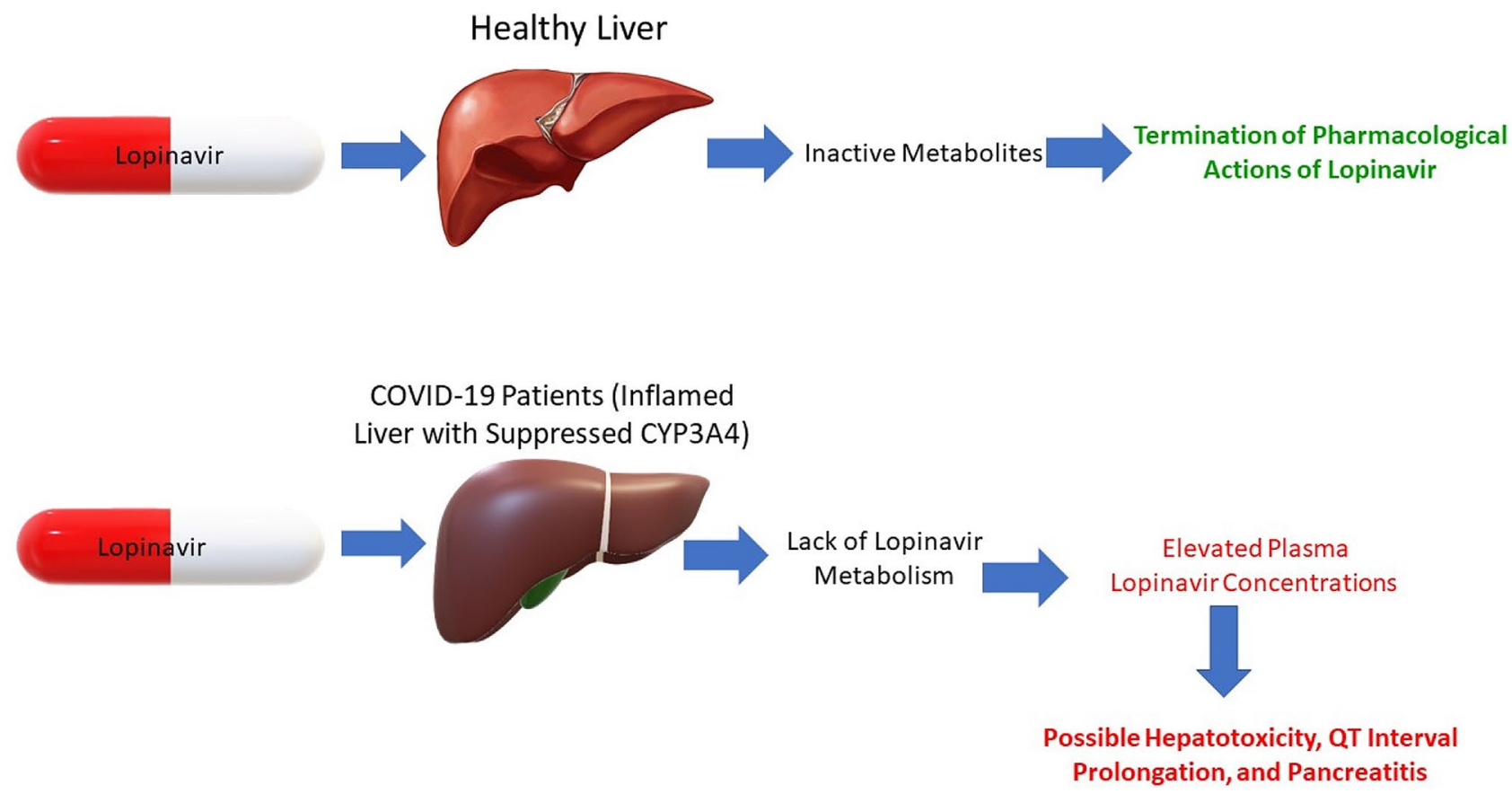

Fig. 2 Difference in drug metabolism and pharmacological outcomes between healthy and inflamed liver in COVID-19 patients. Lopinavir, an anti-retroviral drug that has been repurposed for COVID-19, has been taken as an example, but this prototype flowchart is applicable to all drugs that are metabolized to inactive metabolites by cytochrome P450 enzymes, especially, through the CYP3A4 isoform 
or investigational drugs for SARS-CoV-2 include antivirals (e.g., remdesivir, lopinavir, /ritonavir, umifenovir, favipiravir), antiprotozoal drugs (e.g., hydroxychloroquine, ivermectin), corticosteroids (e.g., dexamethasone, methylprednisolone), and monoclonal antibodies (e.g., tocilizumab, a cocktail to neutralize inflammatory proteins) $[5,66]$.

\subsubsection{Remdesivir and Favipiravir}

Among several drugs deployed for COVID-19 treatment, remdesivir, which is an RNA polymerase inhibitor and an investigational $\mathrm{C}$-adenosine nucleoside prodrug, is one of the few agents that has generated a somewhat positive impact [67]. Like many antiviral prodrugs, it is not fully phosphorylated until it enters a virus cell given its selectivity. Multiple clinical trials have shown it to be a relatively safe medication with linear pharmacokinetics when administered under $225 \mathrm{mg}$ and reversible hepatotoxicity [67]. Several ongoing phase 3 clinical trials evaluated remdesivir for efficacy, and its emergency use authorization was expanded to all patients with moderate COVID-19 [67]. Although no comprehensive studies have been reported on remdesivir metabolism, it has been identified as a substrate for CYP2C8, CYP2D6, and CYP3A4 as well as an inhibitor of CYP3A4 and transporters [4]. The suppression of CYP3A4 expression by concomitant inflammatory conditions could lower the elimination of remdesivir. In addition, its dosing in clinical trials includes a loading dose of $200 \mathrm{mg}$ followed by infusions of $100 \mathrm{mg}$ [67], which suggests that drug-drug or drug-disease interactions may drive the concentrations (> $225 \mathrm{mg}$ ) toward nonlinear pharmacokinetics and an unpredictable dose-toxicity relationship [67].

Favipiravir is another RNA polymerase inhibitor that has been evaluated on COVID-19 patients. It is a substrate of aldehyde oxidase and xanthine oxidase and is an inhibitor of CYP2C8 and aldehyde oxidase. Major adverse effects include hyperuricemia and abnormal liver functions [5]. Due to the non-CYP metabolic pathway of favipiravir [5], it is likely that the pathophysiological factors in COVID-19 patients will not have any significant effect on the disposition of favipiravir.

\subsubsection{Protease Inhibitors: Are we Compounding an Already Existing Problem?}

Originally, a lopinavir/ritonavir protease inhibitor combination was approved for the treatment of HIV. However, this combination has also been evaluated for protease inhibition against different coronavirus family members including against SARS-CoV-2 in vitro and in COVID-19 patients. So far, although there is in vitro antiviral activity, some studies have shown efficacy (e.g., duration of ICU stay, viral load clearance) while others show no difference to the comparator of this combination in COVID patients [68]. However, the combination is known to have significant gastric adverse effects, hepatotoxicity, and pancreatitis [68]. Lopinavir and ritonavir are both CYP3A4 substrates, so there is a potential for elevated levels following inflammation-related downregulation of CYP3A4 expression. Both the agents are also well known for their ability to inhibit CYP3A4. The combination of these drugs also induces other CYPs including CYP2B6, CYP2C9, and CYP2C19 [68]. In addition to the inflammation-related downregulation of CYP3A4 expression, autoinhibition of CYP3A4-mediated metabolism by lopinavir/ritonavir may pose a challenge to their elimination. Considering their ability to cause hepatoxicity, this combination has the potential to add a toxic burden on the liver.

\subsubsection{Chloroquine and Hydroxychloroquine}

During the first month of the pandemic (March 2020), the FDA issued an Emergency Use Authorization for hydroxychloroquine, which they later revoked in June 2020; however, other parts of the world are still using hydroxychloroquine as an investigational treatment and prophylactic agent for COVID-19 [69]. These antimalarial drugs have been proposed to have antiviral action in COVID-19 patients by inhibiting the viral entry and thus decreasing the viral load. Several completed or ongoing clinical trials did not find much success in establishing the antiviral efficacy of chloroquine and hydroxychloroquine [70]. As such, these antimalarial drugs are known to be very toxic because of their cardiotoxicity, hepatological effects, and adverse vision effects [70]. Both of these drugs are metabolized by CYP3A4 and CYP2D6, which suggests that lower CYP3A4 function in the inflammatory condition may drive their metabolism more toward CYP2D6. It is important to recognize that CYP2D6 expression is not induced or suppressed by the typical inflammatory factors and in general by very few chemical agents; however, because of the highly frequent polymorphic presence of CYP2D6 [71], the patients are likely to experience altered elimination of chloroquine and hydroxychloroquine and eventually unpredictable lifethreatening drug-adverse effects.

\subsubsection{Corticosteroids}

Corticosteroids are another group of medications that have emerged as a treatment option for COVID-19 [72]. In the RECOVERY trial, there was a significant risk reduction for patients requiring supplemental oxygen or being ventilated compared to the usual care group [72]. Dexamethasone is both an inducer and a substrate for the CYP3A4 enzyme [73, 74]. Decreased metabolism of dexamethasone may lead to corticosteroid-related acute adverse effects such as hyperglycemia and fluid retention [75]. 


\subsubsection{Supportive Medications}

It is relevant to observe that the standard of care for patients does not include medications for ventilation explicitly, but ventilation does require medication, and many of these patients require ventilation. To be ventilated the patient must first be paralyzed, and to be paralyzed they must be sedated and have analgesia. After ventilation the patient should receive deep venous thrombosis prophylaxis, stress ulcer prophylaxis, and ventilator-associated pneumonia prophylaxis [13]. Propofol is a medication that is commonly used for deep sedation before paralysis. It is metabolized by CYP2B6, which means it is heavily affected by IL-6 [76]. Fentanyl is used for sedation and analgesia and is metabolized by CYP3A4 [76]. Benzodiazepine drugs are largely a CYP3A4 substrate, which suggests potential diseasedrug interactions with this class of drugs. Midazolam is commonly used in producing sedation and is metabolized by CYP3A4 [73]. Most of these medications can be very harmful if the plasma levels are increased following lack of metabolism by inflammation-mediated CYP3A4 or CYP2B6 suppression.

\subsection{Potential Effects of COVID-19 on Medications for Comorbidities}

Along with the COVID-19-related drug therapies, patients often take medications for comorbidities, especially individuals with preexisting conditions/comorbidities are most vulnerable to SARS-CoV-2 infection [7]. Thus, the chance of a COVID-19 patient having disease-drug interactions compared to a non-COVID-19 patient is much higher. In a metaanalysis conducted on patients with comorbidities there were three underlying diseases most common with COVID-19, namely, $16 \%$ of patients were hypertensive, $12.11 \%$ of patients had cardiovascular disease, and $7.87 \%$ of patients had type 2 diabetes [7]. These patients typically take medications that are metabolized by CYP enzymes. CYP3A4 is metabolized by commonly used antihypertensives including most dihydropyridine calcium channel blockers (e.g., amlodipine and nifedipine), all non-dihydropyridine calcium channel blockers (e.g., verapamil and diltiazem), and propranolol [77-80]. Irbesartan and losartan are antihypertensive drugs that are metabolized by CYP2C9 [81]. Cholesterol-lowering drugs such as statins (except pravastatin and rosuvastatin), which are often also used in patients with hypertension, are metabolized by CYP3A4 $[82,83]$. Similarly, antidiabetic agents such as glimepiride, glipizide, and glyburide are metabolized by CYP2C9 [84]. Since IL-6 downregulates the major drug-metabolizing CYP enzymes (e.g., CYP2B6, CYP2C9, and CYP3A4), administration of agents for comorbidities could be detrimental to COVID-19 patients. CYP3A4 suppression is extremely sensitive to IL-6 elevation and gets downregulated even with a minor increase in IL-6 as quickly as within $24 \mathrm{~h}$ [40]. Similarly, CYP2C9 is also downregulated by IL- 6 at higher concentrations. IL- $1 \beta$ also downregulates CAR, which in turn leads to a lower expression of CYP2C9 [40]. Supratherapeutic plasma levels caused by decreased metabolism of antihypertensive medications can lead to hypotension and other related side effects. This can intensify hypotension already caused by systemic infection by SARS-CoV-2. Similarly, higher concentrations of statins can lead to rhabdomyolysis, which can intensify the body aches already experienced by feverish COVID-19 patients [3]. Plasma concentrations of antidiabetic medications, especially the sulfonylureas, above the minimum toxic concentrations can cause dangerous hypoglycemia, which is already aggravated in the patient by difficulty with eating and intubation [3].

Along with the disease-drug interactions of comorbidity therapeutics, it is extremely critical to understand that the investigational COVID-19 therapies also modulate the CYP functionality. By administering the COVID-19 medications we may be compounding already existing disposition-related issues of drugs for comorbidity. For example, ritonavir is a strong CYP3A4 inhibitor, and already suppressed CYP3A4 functions can be further abolished by ritonavir, eventually totally blocking the elimination of antihypertensive, antidiabetic, and cholesterol-lowering drugs [68]. Similar metabolic alterations of drugs for comorbidities could be experienced by COVID-19 investigational drugs, such as lopinavir and tocilizumab, known to inhibit or induce CYP3A4 or CYP2C9 enzymes [39, 85]. Thus, decreased elimination of antihypertensives, cholesterol-lowering, and antidiabetic drugs through dysregulation of CYP enzymes can be fatal for the patients if they are not monitored for appropriate toxic end points.

\section{Conclusions and Recommendations}

\subsection{Drugs to Decrease Inflammation and Reverse CYP Downregulation}

Although lowering the viral load and eliminating the source of inflammation are the primary strategies of SARS-CoV-2 treatment, use of anti-inflammatory medications to neutralize the inflammatory proteins or signaling may be an indirect but effective way to attenuate several pathophysiological symptoms including reversing the downregulation of CYP enzymes. Currently, two monoclonal antibody cocktail preparations (LY-CoV555, REGN-COV2) designed to neutralize 
SARS-CoV-2 have been submitted for the FDA's emergency use authorization for COVID-19 patients [86]. In addition, tocilizumab, a monoclonal antibody against the IL-6 receptor used in autoimmune disorders and to prevent the lifethreatening 'cytokine storm', has been shown in in vitro studies to attenuate or abolish the suppressive effects of IL-6 on CYP3A4, CYP2B6, CYP2C9, and CYP2C19 mRNA and metabolism $[39,87]$. Similarly, use of anti-TNF $\alpha$ antibodies (e.g., infliximab, adalimumab) can also be a potential way of lowering the life-threatening inflammation as well as ensuring that the patient has the optimum CYP-mediated drug metabolism capacity to eliminate the COVID-19- and comorbidity-related drugs [88]. Health supplements such as melatonin and vitamin D have also been touted as adjuvant therapy for their ability to reduce inflammation and have the potential to attenuate the 'cytokine storm' including IL- 6 and restore the CYP expression and metabolism [5, 89]. Melatonin also helps to remove reactive oxygen species that are formed from the tissue damage and may be able to promote healing [89]. Therefore, we hypothesize that COVID-19 patients with suppressed drug metabolism may demonstrate improved drug clearance following treatment with inflammation-lowering agents. Indeed, tocilizumab, an IL-6 blocker anti-inflammatory antibody, significantly lowered the trough lopinavir concentration in COVID-19 patients, which is indicative of enhanced drug clearance and plausible reversal of inflammation-related decreased disposition [58].

\subsection{Use of Alternative Drugs for Comorbidities During COVID-19}

The comorbidities that are often associated with COVID19 have a plethora of therapeutic options. Patients with hypertension and heart failure can use ACE inhibitors, which are not largely metabolized by CYP enzymes [90]. There may be some additional benefit for patients because the virus is spread through the ACE2 receptor, and blocking of the ACE2 receptor might minimize the entry into the body. If patients have had angioedema in the past, have hyperkalemia, or have exceptional risk of an acute cardiac injury, they may be able to use a thiazide diuretic, which also has very little CYP metabolism [91]. Most beta-blockers are metabolized by CYP2D6 and should be used with caution because of hydroxychloroquine-mediated inhibition of CYP2D6 if used concomitantly [92].

Similarly, for diabetes there are several options for patients. Sulfonylureas are a class of drugs that needs dose adjustment or discontinuation due to the inherent risk of hypoglycemia when given to non-COVID-19 patients [93]. Since CYP2C9 enzyme and CAR (receptor regulating the enzyme) are affected by COVID-19-related inflammation [84], it is likely that sulfonylureas will accumulate, leading to more severe hypoglycemia. In case of cholesterollowering drugs, rosuvastatin is not primarily metabolized by CYPs, and $90 \%$ of the drug is excreted in feces, which will be a good choice compared to atorvastatin/simvastatin and other CYP3A4 substrates [83]. The antidiabetic drugs that are not hepatically cleared, e.g., liraglutide or semaglutide, should be considered [94]. In either of the cases, if stabilization of the patients on a certain class of CYP-metabolized drugs is a priority, then dose adjustment for the agents for comorbidity will be more desirable.

\subsection{Timeline of CYP Suppression and Decreased Drug Metabolism in COVID-19 Patients}

From the currently available information, it is very difficult to infer how quickly the CYP expression and metabolism will be suppressed after the initial SARS-CoV-2 infection or how long the suppression would last. In studies where cytokines were measured, the laboratory tests were typically done $2-5$ days after the patient was admitted [26]. In the normal course of a COVID-19 infection, patients are not admitted until an average of 7 days after the they are infected. In vitro studies with cytokines and other inflammatory proteins have shown that CYP mRNA reaches maximum suppression as quickly as $24 \mathrm{~h}$ from exposure to cytokines [95]. Therefore, it is likely that during the initial phase of infection patients will experience downregulation of CYP expression and lower metabolic capacity. In a longitudinal study, Liu et al. provided good insight into the difference in IL-6 levels between severe and mild COVID-19 patients [96]. In severe patients, IL-6 levels were elevated to an average of $70 \mathrm{pg} / \mathrm{ml}$ at $<3$ days after disease onset, and the elevated levels continued until 15 days when the levels started to decrease [96]. In patients with mild disease, IL-6 does not have any peak and maintained an average level of $20 \mathrm{pg} / \mathrm{ml}$ throughout the course of the illness [96]. Thus, it is likely that patients could be experiencing metabolism issues even before they are symptomatic, admitted to the hospital, or liver dysfunction is suspected. Since patients may experience compromised metabolic capacity irrespective of the onset/length of COVID-19 and extent of liver dysfunction, it is also plausible that along with the 'cytokine storm' toxic drug levels and increased hepatotoxicity from drugs for comorbidities might be contributing to the abnormal liver health in COVID-19 patients. Except for in a small percentage of patients who might experience severe liver damage, hepatocytes have remarkable regenerative capabilities [30]. Analogous to drug-drug interactions, CYP enzymes usually recover very quickly after the offending agents are no longer in the body. In this case, the primary offending agents, i.e., the inflammatory cytokines, are known to recede to normal levels around 
15 days after the onset of the infection, which will allow the CYPs to recover in a gradual manner [9, 18-24]. It is critical that cytokine levels, liver function tests, and plasma for narrow therapeutic index drugs are measured at different time points after hospitalization and analyzed for restoration of the CYP-mediated metabolic system.

\subsection{Recommendations for the Frontline Healthcare Professionals (Physicians, Nurses, Pharmacists)}

In conclusion, COVID-19 patients experience a wide range of pathophysiological changes including immune responsebased inflammation. A 'cytokine storm' or very high levels of cytokines have been identified in SARS-CoV-2 infected individuals, especially when they are severely ill (e.g., in the ICU, on ventilation, non-survivors) $[9,10]$. In correlation with the inflammatory proteins, liver enzyme levels also appear to be more compromised in severely ill patients than in individuals with mild symptoms [9, 18, 19, 22]. Over the years, it has been well established in non-SARS-CoV-2 viral infections that elevated cytokine levels can strongly suppress CYP regulation and lower hepatic and other organ drug clearance [46, 47, 51]. This opens the window for further complications in COVID-19 patients when elevated drug concentrations can lead to liver and other organ dysfunction. It is pertinent to recognize that COVID-19 patients might experience polypharmacy due to the drugs needed to treat the disease and symptoms as well as the agents for comorbidities prevalent in COVID-19 patients [4, 7]. Plasma concentrations of COVID-19 drugs such as lopinavir and darunavir are increased in COVID-19 patients [54, 57], and this scenario can be extended to other medications as well.

It is imperative that additional perspectives be added in the treatment plans of severe COVID-19 patients. Pharmacists and physicians often pay so much attention to drugdrug interactions, but the drug-disease interactions are not considered. Though it can be hard to capture the effects of inflammatory proteins, CYP regulation, and drug disposition in COVID-19 patients in real time, the availability of physiologically based simulation platforms (e.g., GastroPlus, SimCyp) should enable the researchers to predict the potential metabolic status of the patients regarding the drugs for COVID-19 and comorbidities. Clinicians need to pay special attention to the CYP3A4 substrates because of the potent suppressive effects of IL- 6 and other cytokines on this isoform and because the majority of the drugs in the clinic are metabolized by this isoform $[46,47,51]$. It is understandable that it might not always be practical to switch the drugs for comorbidities, especially for chronic diseases like hypertension, diabetes, and hyperlipidemia, but narrow therapeutic index drugs should be effectively recognized for discontinuation or dose adjustment. Measurement of plasma drug levels at certain intervals for COVID-19 investigational drugs (e.g., hydroxychloroquine) and drugs for comorbidities is needed to establish the therapeutic window in the infected individuals. This will facilitate therapeutic drug monitoring and can minimize adverse drug effects as well as elevated drug concentration-related liver dysfunction among COVID-19 patients. For outpatient individuals, the patient and/or the caregivers should be counseled about the drug toxicities from elevated plasma levels and desired interventions. It is important to note that significantly higher levels of inflammatory cytokines were mostly seen in severely ill COVID-19 patients, and they are the target population for monitoring and intervention [9, 18-24]. This could also be the reason that the compromised metabolic status has not drawn much attention yet since patients with severe cases of COVID-19 typically experience myriad symptoms that mask the toxicities from the elevated drug plasma levels and a number of patients do not survive. As a result, we predict that a suppressed CYP metabolic system and compromised drug metabolism might contribute to the organ damage and higher mortality rate in patients severely ill from COVID- 19 . Overall, the knowledge about pathophysiology of COVID19 and understanding of the CYP expression status and drug metabolism and pharmacokinetic scope will potentially minimize drug-related toxicity and optimize the pharmacotherapy of infected individuals.

\section{Compliance with Ethical Standards}

Funding No funding was received for this article.

Conflict of interest Dr. Subrata Deb and Mr. Scott Arrighi declare that they have no conflict of interest.

\section{References}

1. World Health Organization (WHO). WHO Coronavirus Disease (COVID-19) Dashboard. 2020. https://covid19.who.int/. Accessed 14 Oct 2020.

2. World Health Organization (WHO). Coronavirus disease (COVID-19) pandemic. 2020. https://www.who.int/emergencie s/diseases/novel-coronavirus-2019. Accessed 14 Oct 2020.

3. Rodriguez-Morales AJ, Cardona-Ospina JA, Gutierrez-Ocampo E, Villamizar-Pena R, Holguin-Rivera Y, Escalera-Antezana JP, et al. Clinical, laboratory and imaging features of COVID-19: a systematic review and meta-analysis. Travel Med Infect Dis. 2020;34:101623. https://doi.org/10.1016/j.tmaid.2020.101623.

4. Yang J, Zheng Y, Gou X, Pu K, Chen Z, Guo Q, et al. Prevalence of comorbidities and its effects in patients infected with SARSCoV-2: a systematic review and meta-analysis. Int J Infect Dis. 2020;94:91-5. https://doi.org/10.1016/j.ijid.2020.03.017.

5. Dhama K, Sharun K, Tiwari R, Dadar M, Malik YS, Singh $\mathrm{KP}$, et al. COVID-19, an emerging coronavirus infection: advances and prospects in designing and developing vaccines, immunotherapeutics, and therapeutics. Hum Vaccin 
Immunother. 2020;16(6):1232-8. https://doi.org/10.1080/21645 515.2020.1735227.

6. Kang S, Peng W, Zhu Y, Lu S, Zhou M, Lin W, et al. Recent progress in understanding 2019 novel coronavirus (SARS$\mathrm{CoV}-2)$ associated with human respiratory disease: detection, mechanisms and treatment. Int $\mathrm{J}$ Antimicrob Agents. 2020;55(5):105950. https://doi.org/10.1016/j.ijantimica g.2020.105950.

7. Emami A, Javanmardi F, Pirbonyeh N, Akbari A. Prevalence of underlying diseases in hospitalized patients with COVID-19: a systematic review and meta-analysis. Arch Acad Emerg Med. 2020;8(1):e35.

8. Liu K, Chen Y, Lin R, Han K. Clinical features of COVID-19 in elderly patients: a comparison with young and middle-aged patients. J Infect. 2020;80(6):e14-8. https://doi.org/10.1016/j. jinf.2020.03.005

9. Gao Y, Li T, Han M, Li X, Wu D, Xu Y, et al. Diagnostic utility of clinical laboratory data determinations for patients with the severe COVID-19. J Med Virol. 2020;92(7):791-6. https://doi. org/10.1002/jmv.25770.

10. Guo T, Fan Y, Chen M, Wu X, Zhang L, He T, et al. Cardiovascular implications of fatal outcomes of patients with coronavirus disease 2019 (COVID-19). JAMA Cardiol. 2020;5(7):811-8. https://doi.org/10.1001/jamacardio.2020.1017.

11. Hamming I, Timens W, Bulthuis ML, Lely AT, Navis G, van Goor H. Tissue distribution of ACE2 protein, the functional receptor for SARS coronavirus. A first step in understanding SARS pathogenesis. J Pathol. 2004;203(2):631-7. https://doi. org/10.1002/path.1570.

12. U.S. Food and Drug Administration. FDA Drug Shortages. 2020. https://www.accessdata.fda.gov/scripts/drugshortages/. Accessed 14 Oct 2020.

13. Higgs A, McGrath BA, Goddard C, Rangasami J, Suntharalingam $\mathrm{G}$, Gale R, et al. Guidelines for the management of tracheal intubation in critically ill adults. Br J Anaesth. 2018;120(2):323-52. https://doi.org/10.1016/j.bja.2017.10.021.

14. Salehi S, Abedi A, Balakrishnan S, Gholamrezanezhad A. Coronavirus disease 2019 (COVID-19): a systematic review of imaging findings in 919 patients. Am J Roentgenol. 2020;215(1):8793. https://doi.org/10.2214/AJR.20.23034.

15. Mehta P, McAuley DF, Brown M, Sanchez E, Tattersall RS, Manson JJ, et al. COVID-19: consider cytokine storm syndromes and immunosuppression. Lancet. 2020;395(10229):1033-4. https ://doi.org/10.1016/S0140-6736(20)30628-0.

16. Conti P, Ronconi G, Caraffa A, Gallenga CE, Ross R, Frydas I, et al. Induction of pro-inflammatory cytokines (IL-1 and IL-6) and lung inflammation by Coronavirus-19 (COVI-19 or SARSCoV-2): anti-inflammatory strategies. J Biol Regul Homeost Agents. 2020;34(2):327-31. https://doi.org/10.23812/CONTI-E.

17. Li J, Fan JG. Characteristics and mechanism of liver injury in 2019 coronavirus disease. J Clin Transl Hepatol. 2020;8(1):13-7. https://doi.org/10.14218/JCTH.2020.00019.

18. Wang F, Yang Y, Dong K, Yan Y, Zhang S, Ren H, et al. Clinical characteristics of 28 patients with diabetes and Covid-19 in Wuhan, China. Endocr Pract. 2020;26(6):668-74. https://doi. org/10.4158/EP-2020-0108.

19. Chen T, Wu D, Chen H, Yan W, Yang D, Chen G, et al. Clinical characteristics of 113 deceased patients with coronavirus disease 2019: retrospective study. BMJ. 2020;368:m1091. https:// doi.org/10.1136/bmj.m1091.

20. Chen Q, Xu L, Dai Y, Ling Y, Mao J, Qian J, et al. Cardiovascular manifestations in severe and critical patients with COVID19. Clin Cardiol. 2020;43(7):796-802. https://doi.org/10.1002/ clc. 23384
21. Zhu Z, Cai T, Fan L, Lou K, Hua X, Huang Z, et al. Clinical value of immune-inflammatory parameters to assess the severity of coronavirus disease 2019. Int J Infect Dis. 2020;95:332-9. https://doi.org/10.1016/j.ijid.2020.04.041.

22. Huang H, Song B, Xu Z, Jiao Y, Huang L, Zhao P, et al. Predictors of coronavirus disease 2019 severity: a retrospective study of 64 cases. Jpn J Infect Dis. 2019. https://doi.org/10.7883/yoken JJID.2020.298.

23. Petrey AC, Qeadan F, Middleton EA, Pinchuk IV, Campbell RA, Beswick EJ. Cytokine release syndrome in COVID-19: innate immune, vascular, and platelet pathogenic factors differ in severity of disease and sex. J Leukoc Biol. 2020. https://doi. org/10.1002/JLB.3COVA0820-410RRR.

24. Zou L, Dai L, Zhang Y, Fu W, Gao Y, Zhang Z, et al. Clinical characteristics and risk factors for disease severity and death in patients with coronavirus disease 2019 in Wuhan, China. Front Med (Lausanne). 2020;7:532. https://doi.org/10.3389/ fmed.2020.00532.

25. Russell B, Moss C, George G, Santaolalla A, Cope A, Papa S, et al. Associations between immune-suppressive and stimulating drugs and novel COVID-19-a systematic review of current evidence. Ecancermedicalscience. 2020;14:1022. https://doi. org/10.3332/ecancer.2020.1022.

26. Huang C, Wang Y, Li X, Ren L, Zhao J, Hu Y, et al. Clinical features of patients infected with 2019 novel coronavirus in Wuhan, China. Lancet. 2020;395(10223):497-506. https://doi. org/10.1016/S0140-6736(20)30183-5.

27. Musa S. Hepatic and gastrointestinal involvement in coronavirus disease 2019 (COVID-19): what do we know till now? Arab J Gastroenterol. 2020;21(1):3-8. https://doi.org/10.1016/j. ajg.2020.03.002.

28. Bangash MN, Patel J, Parekh D. COVID-19 and the liver: little cause for concern. Lancet Gastroenterol Hepatol. 2020;5(6):529 30. https://doi.org/10.1016/S2468-1253(20)30084-4.

29. Liu F, Xu A, Zhang Y, Xuan W, Yan T, Pan K, et al. Patients of COVID-19 may benefit from sustained Lopinavir-combined regimen and the increase of Eosinophil may predict the outcome of COVID-19 progression. Int J Infect Dis. 2020;95:183-91. https ://doi.org/10.1016/j.ijid.2020.03.013.

30. Deb S, Puthanveetil P, Sakharkar P. A population-based crosssectional study of the association between liver enzymes and lipid levels. Int J Hepatol. 2018;2018:1286170. https://doi. org/10.1155/2018/1286170.

31. Sakharkar P, Deb S, Mashayekhi N. Association between polymorphisms in cytokine gene and viral infections in renal and liver transplant recipients: a systematic review. J Pharm Pharm Sci. 2020;23(1):109-31. https://doi.org/10.18433/jpps30961.

32. Newsome PN, Cramb R, Davison SM, Dillon JF, Foulerton M, Godfrey EM, et al. Guidelines on the management of abnormal liver blood tests. Gut. 2018;67(1):6-19. https://doi.org/10.1136/ gutjnl-2017-314924.

33. Kwo PY, Cohen SM, Lim JK. ACG clinical guideline: evaluation of abnormal liver chemistries. Am J Gastroenterol. 2017;112(1):18-35. https://doi.org/10.1038/ajg.2016.517.

34. Feng G, Zheng KI, Yan QQ, Rios RS, Targher G, Byrne CD, et al. COVID-19 and liver dysfunction: current insights and emergent therapeutic strategies. J Clin Transl Hepatol. 2020;8(1):18-24. https://doi.org/10.14218/JCTH.2020.00018.

35. Hong KS, Lee KH, Chung JH, Shin KC, Choi EY, Jin HJ, et al. Clinical features and outcomes of 98 patients hospitalized with SARS-CoV-2 infection in Daegu, South Korea: a brief descriptive study. Yonsei Med J. 2020;61(5):431-7. https://doi. org/10.3349/ymj.2020.61.5.431.

36. Sverrisdottir E, Lund TM, Olesen AE, Drewes AM, Christrup LL, Kreilgaard M. A review of morphine and morphine-6-glucuronide's pharmacokinetic-pharmacodynamic relationships in 
experimental and clinical pain. Eur J Pharm Sci. 2015;74:45-62. https://doi.org/10.1016/j.ejps.2015.03.020.

37. Renton KW. Regulation of drug metabolism and disposition during inflammation and infection. Expert Opin Drug Metab Toxicol. 2005;1(4):629-40. https://doi.org/10.1517/17425 255.1.4.629.

38. Callahan SM, Wonganan P, Croyle MA. Molecular and macromolecular alterations of recombinant adenoviral vectors do not resolve changes in hepatic drug metabolism during infection. Virol J. 2008;5:111. https://doi.org/10.1186/1743-422X-5-111.

39. Kim S, Ostor AJ, Nisar MK. Interleukin-6 and cytochrome-P450, reason for concern? Rheumatol Int. 2012;32(9):2601-4. https:// doi.org/10.1007/s00296-012-2423-3.

40. Li AP, Yang Q, Vermet H, Raoust N, Klieber S, Fabre G. Evaluation of human hepatocytes under prolonged culture in a novel medium for the maintenance of hepatic differentiation: results with the model pro-inflammatory cytokine interleukin 6 . Drug Metab Lett. 2014;8(1):12-8. https://doi.org/10.2174/1872312808 01140929155351.

41. Croyle MA. Long-term virus-induced alterations of CYP3Amediated drug metabolism: a look at the virology, immunology and molecular biology of a multi-faceted problem. Expert Opin Drug Metab Toxicol. 2009;5(10):1189-211. https://doi. org/10.1517/17425250903136748.

42. Aitken AE, Morgan ET. Gene-specific effects of inflammatory cytokines on cytochrome P450 2C, 2B6 and 3A4 mRNA levels in human hepatocytes. Drug Metab Dispos. 2007;35(9):1687-93. https://doi.org/10.1124/dmd.107.015511.

43. Pascussi JM, Dvorak Z, Gerbal-Chaloin S, Assenat E, Maurel P, Vilarem MJ. Pathophysiological factors affecting CAR gene expression. Drug Metab Rev. 2003;35(4):255-68. https://doi. org/10.1081/dmr-120026394.

44. Rasmussen MK, Bertholdt L, Gudiksen A, Pilegaard H, Knudsen JG. Impact of fasting followed by short-term exposure to interleukin-6 on cytochrome P450 mRNA in mice. Toxicol Lett. 2018;282:93-9. https://doi.org/10.1016/j.toxlet.2017.10.011.

45. Moreau A, Le Vee M, Jouan E, Denizot C, Parmentier Y, Fardel O. Effect of gevokizumab on interleukin-1beta-mediated cytochrome P450 3A4 and drug transporter repression in cultured human hepatocytes. Eur J Drug Metab Pharmacokinet. 2017;42(5):871-8. https://doi.org/10.1007/s13318-017-0406-1.

46. Cheng PY, Morgan ET. Hepatic cytochrome P450 regulation in disease states. Curr Drug Metab. 2001;2(2):165-83. https://doi. org/10.2174/1389200013338676.

47. Renton KW. Cytochrome P450 regulation and drug biotransformation during inflammation and infection. Curr Drug Metab. 2004;5(3):235-43. https://doi.org/10.2174/1389200043335559.

48. Chen YL, Le Vraux V, Leneveu A, Dreyfus F, Stheneur A, Florentin I, et al. Acute-phase response, interleukin-6, and alteration of cyclosporine pharmacokinetics. Clin Pharmacol Ther. 1994;55(6):649-60. https://doi.org/10.1038/clpt.1994.82.

49. Machavaram KK, Almond LM, Rostami-Hodjegan A, Gardner I, Jamei M, Tay S, et al. A physiologically based pharmacokinetic modeling approach to predict disease-drug interactions: suppression of CYP3A by IL-6. Clin Pharmacol Ther. 2013;94(2):260-8. https://doi.org/10.1038/clpt.2013.79.

50. Varkhede N, Patel N, Chang W, Ruterbories K, Forrest ML. A semi-physiologically based pharmacokinetic model describing the altered metabolism of midazolam due to inflammation in mice. Pharm Res. 2018;35(8):162. https://doi.org/10.1007/s1109 5-018-2447-9.

51. Seifert SM, Castillo-Mancilla JR, Erlandson KM, Anderson PL. Inflammation and pharmacokinetics: potential implications for HIV-infection. Expert Opin Drug Metab Toxicol. 2017;13(6):641-50. https://doi.org/10.1080/17425 255.2017.1311323.
52. Sorgel F, Malin JJ, Hagmann H, Kinzig M, Bilal M, Eichenauer DA, et al. Pharmacokinetics of remdesivir in a COVID-19 patient with end-stage renal disease on intermittent haemodialysis. J Antimicrob Chemother. 2020. https://doi.org/10.1093/jac/dkaa5 00 .

53. VEKLURY® (remdesivir) Package Insert. https://www.veklu ryhcp.com/. Accessed 17 Dec 2020.

54. Cojutti PG, Londero A, Della Siega P, Givone F, Fabris M, Biasizzo J, et al. Comparative population pharmacokinetics of Darunavir in SARS-CoV-2 patients vs. HIV patients: the role of Interleukin-6. Clin Pharmacokinet. 2020;59(10):1251-60. https ://doi.org/10.1007/s40262-020-00933-8.

55. Le MP, Jaquet P, Patrier J, Wicky PH, Le Hingrat Q, Veyrier $\mathrm{M}$, et al. Pharmacokinetics of lopinavir/ritonavir oral solution to treat COVID-19 in mechanically ventilated ICU patients. J Antimicrob Chemother. 2020;75(9):2657-60. https://doi.org/10.1093/ jac/dkaa261.

56. Thakur A, Tan SPF, Chan JCY. Physiologically-based pharmacokinetic modeling to predict the clinical efficacy of the coadministration of lopinavir and ritonavir against SARS-CoV-2. Clin Pharmacol Ther. 2020;108(6):1176-84. https://doi.org/10.1002/ cpt.2014.

57. Alvarez JC, Moine P, Davido B, Etting I, Annane D, Larabi IA, et al. Population pharmacokinetics of lopinavir/ritonavir in Covid-19 patients. Eur J Clin Pharmacol. 2020. https://doi. org/10.1007/s00228-020-03020-w.

58. Marzolini C, Stader F, Stoeckle M, Franzeck F, Egli A, Bassetti S, et al. Effect of systemic inflammatory response to SARS-CoV-2 on lopinavir and hydroxychloroquine plasma concentrations. Antimicrob Agents Chemother. 2020. https://doi. org/10.1128/AAC.01177-20.

59. Schoergenhofer C, Jilma B, Stimpfl T, Karolyi M, Zoufaly A. Pharmacokinetics of lopinavir and ritonavir in patients hospitalized with coronavirus disease 2019 (COVID-19). Ann Intern Med. 2020;173(8):670-2. https://doi.org/10.7326/M20-1550.

60. Meziyerh S, Zwart TC, van Etten RW, Janson JA, van Gelder T, Alwayn IPJ, et al. Severe COVID-19 in a renal transplant recipient: a focus on pharmacokinetics. Am J Transplant. 2020;20(7):1896-901. https://doi.org/10.1111/ajt.15943.

61. Cai Q, Huang D, Yu H, Zhu Z, Xia Z, Su Y, et al. COVID-19: abnormal liver function tests. J Hepatol. 2020;73(3):566-74. https://doi.org/10.1016/j.jhep.2020.04.006.

62. Shokri Afra H, Amiri-Dashatan N, Ghorbani F, Maleki I, RezaeiTavirani M. Positive association between severity of COVID-19 infection and liver damage: a systematic review and meta-analysis. Gastroenterol Hepatol Bed Bench. 2020;13(4):292-304.

63. Chen M, Suzuki A, Borlak J, Andrade RJ, Lucena MI. Druginduced liver injury: interactions between drug properties and host factors. J Hepatol. 2015;63(2):503-14. https://doi. org/10.1016/j.jhep.2015.04.016.

64. Christensen H, Hermann M. Immunological response as a source to variability in drug metabolism and transport. Front Pharmacol. 2012;3:8. https://doi.org/10.3389/fphar.2012.00008.

65. Viani A, Rizzo G, Carrai M, Pacifici GM. Interindividual variability in the concentrations of albumin and alpha-1-acid glycoprotein in patients with renal or liver disease, newborns and healthy subjects: implications for binding of drugs. Int J Clin Pharmacol Ther Toxicol. 1992;30(4):128-33.

66. World Health Organization (WHO). R\&D Blueprint and COVID-19 2020. https://www.who.int/teams/blueprint/covid -19. Accessed 14 Oct 2020.

67. Doggrell SA. Remdesivir, a remedy or a ripple in severe COVID-19? Expert Opin Investig Drugs. 2020. https://doi. org/10.1080/13543784.2020.1821645.

68. Cao B, Wang Y, Wen D, Liu W, Wang J, Fan G, et al. A trial of lopinavir-ritonavir in adults hospitalized with severe Covid-19. 
N Engl J Med. 2020;382(19):1787-99. https://doi.org/10.1056/ NEJMoa2001282.

69. U.S. Food and Drug Administration. Coronavirus (COVID-19) Update: FDA Revokes Emergency Use Authorization for Chloroquine and Hydroxychloroquine. 2020. https://www.fda.gov/ news-events/press-announcements/coronavirus-covid-19-updat e-fda-revokes-emergency-use-authorization-chloroquine-and. Accessed 14 Oct 2020.

70. Cortegiani A, Ingoglia G, Ippolito M, Giarratano A, Einav S. A systematic review on the efficacy and safety of chloroquine for the treatment of COVID-19. J Crit Care. 2020;57:279-83. https ://doi.org/10.1016/j.jcrc.2020.03.005.

71. Nefic H. The genetic variation of CYP2D6 gene in the Bosnian population. Med Arch. 2018;72(6):396-400. https://doi. org/10.5455/medarh.2018.72.396-400.

72. Group RC, Horby P, Lim WS, Emberson JR, Mafham M, Bell JL, et al. Dexamethasone in hospitalized patients with Covid-19preliminary report. N Engl J Med. 2020. https://doi.org/10.1056/ NEJMoa2021436.

73. Doi M, Kajikawa N, Aiba T. Effects of dexamethasone to reverse decreased hepatic midazolam metabolism in rats with acute renal failure. Xenobiotica. 2020;50(5):506-14. https://doi. org/10.1080/00498254.2019.1655680.

74. Deb S, Pandey M, Adomat H, Guns ES. Cytochrome P450 3A-mediated microsomal biotransformation of 1alpha,25dihydroxyvitamin D3 in mouse and human liver: drug-related induction and inhibition of catabolism. Drug Metab Dispos. 2012;40(5):907-18. https://doi.org/10.1124/dmd.111.041681.

75. Kadmiel M, Cidlowski JA. Glucocorticoid receptor signaling in health and disease. Trends Pharmacol Sci. 2013;34(9):518-30. https://doi.org/10.1016/j.tips.2013.07.003.

76. Meyer MR, Maurer HH. Absorption, distribution, metabolism and excretion pharmacogenomics of drugs of abuse. Pharmacogenomics. 2011;12(2):215-33. https://doi.org/10.2217/ pgs.10.171.

77. Katoh M, Nakajima M, Yamazaki H, Yokoi T. Inhibitory potencies of 1,4-dihydropyridine calcium antagonists to P-glycoprotein-mediated transport: comparison with the effects on CYP3A4. Pharm Res. 2000;17(10):1189-97. https://doi. org/10.1023/a:1007568811691.

78. Sutton D, Butler AM, Nadin L, Murray M. Role of CYP3A4 in human hepatic diltiazem N-demethylation: inhibition of CYP3A4 activity by oxidized diltiazem metabolites. J Pharmacol Exp Ther. 1997;282(1):294-300.

79. Tateishi T, Ohashi K, Fujimura A, Ebihara A. The influence of diltiazem versus cimetidine on propranolol metabolism. J Clin Pharmacol. 1992;32(12):1099-104.

80. Zhang Y, Guo X, Lin ET, Benet LZ. Overlapping substrate specificities of cytochrome $\mathrm{P} 4503 \mathrm{~A}$ and P-glycoprotein for a novel cysteine protease inhibitor. Drug Metab Dispos. 1998;26(4):360-6.

81. McCrea JB, Cribb A, Rushmore T, Osborne B, Gillen L, Lo MW, et al. Phenotypic and genotypic investigations of a healthy volunteer deficient in the conversion of losartan to its active metabolite E-3174. Clin Pharmacol Ther. 1999;65(3):348-52. https://doi. org/10.1016/S0009-9236(99)70114-1.

82. Cook CS, Berry LM, Kim DH, Burton EG, Hribar JD, Zhang L. Involvement of CYP3A in the metabolism of eplerenone in humans and dogs: differential metabolism by CYP3A4 and CYP3A5. Drug Metab Dispos. 2002;30(12):1344-51. https://doi. org/10.1124/dmd.30.12.1344.

83. Neuvonen PJ, Jalava KM. Itraconazole drastically increases plasma concentrations of lovastatin and lovastatin acid. Clin Pharmacol Ther. 1996;60(1):54-61. https://doi.org/10.1016/ S0009-9236(96)90167-8.
84. Suzuki K, Yanagawa T, Shibasaki T, Kaniwa N, Hasegawa R, Tohkin M. Effect of CYP2C9 genetic polymorphisms on the efficacy and pharmacokinetics of glimepiride in subjects with type 2 diabetes. Diabetes Res Clin Pract. 2006;72(2):148-54. https:// doi.org/10.1016/j.diabres.2005.09.019.

85. Yao TT, Qian JD, Zhu WY, Wang Y, Wang GQ. A systematic review of lopinavir therapy for SARS coronavirus and MERS coronavirus-A possible reference for coronavirus disease-19 treatment option. J Med Virol. 2020;92(6):556-63. https://doi. org/10.1002/jmv.25729.

86. U.S. National Library of Medicine. ClinicalTrials.gov is a database of privately and publicly funded clinical studies conducted around the world. 2020. https://clinicaltrials.gov/. Accessed 14 Oct 2020.

87. Mimura H, Kobayashi K, Xu L, Hashimoto M, Ejiri Y, Hosoda $\mathrm{M}$, et al. Effects of cytokines on CYP3A4 expression and reversal of the effects by anti-cytokine agents in the three-dimensionally cultured human hepatoma cell line FLC-4. Drug Metab Pharmacokinet. 2015;30(1):105-10. https://doi.org/10.1016/j. dmpk.2014.09.004.

88. Chima M, Lebwohl M. TNF inhibitors for psoriasis. Semin Cutan Med Surg. 2018;37(3):134-42. https://doi.org/10.12788 /j.sder.2018.039.

89. Zhang R, Wang X, Ni L, Di X, Ma B, Niu S, et al. COVID19: melatonin as a potential adjuvant treatment. Life Sci. 2020;250:117583. https://doi.org/10.1016/j.lfs.2020.117583.

90. Hoyer J, Schulte KL, Lenz T. Clinical pharmacokinetics of angiotensin converting enzyme (ACE) inhibitors in renal failure. Clin Pharmacokinet. 1993;24(3):230-54. https://doi. org/10.2165/00003088-199324030-00005.

91. Ellison DH. Clinical pharmacology in diuretic use. Clin J Am Soc Nephrol. 2019;14(8):1248-57. https://doi.org/10.2215/ CJN.09630818.

92. Lee JY, Vinayagamoorthy N, Han K, Kwok SK, Ju JH, Park KS, et al. Association of polymorphisms of cytochrome P450 2D6 with blood hydroxychloroquine levels in patients with systemic lupus erythematosus. Arthritis Rheumatol. 2016;68(1):184-90. https://doi.org/10.1002/art.39402.

93. Matsuoka A, Hirota Y, Takeda A, Kishi M, Hashimoto N, Ohara $\mathrm{T}$, et al. Relationship between glycated hemoglobin level and duration of hypoglycemia in type 2 diabetes patients treated with sulfonylureas: a multicenter cross-sectional study. J Diabetes Investig. 2020;11(2):417-25. https://doi.org/10.1111/jdi.13132.

94. Knudsen LB, Lau J. The discovery and development of liraglutide and semaglutide. Front Endocrinol (Lausanne). 2019;10:155. https://doi.org/10.3389/fendo.2019.00155.

95. Lundgren M, Darnerud PO, Molin Y, Lilienthal H, Blomberg J, Ilback NG. Viral infection and PBDE exposure interact on CYP gene expression and enzyme activities in the mouse liver. Toxicology. 2007;242(1-3):100-8. https://doi.org/10.1016/j. tox.2007.09.014.

96. Liu J, Li S, Liu J, Liang B, Wang X, Wang H, et al. Longitudinal characteristics of lymphocyte responses and cytokine profiles in the peripheral blood of SARS-CoV-2 infected patients. EBioMedicine. 2020;55:102763. https://doi.org/10.1016/j.ebiom 2020.102763

97. Zhang Y, Zheng L, Liu L, Zhao M, Xiao J, Zhao Q. Liver impairment in COVID-19 patients: a retrospective analysis of 115 cases from a single centre in Wuhan city, China. Liver Int. 2020;40(9):2095-103. https://doi.org/10.1111/liv.14455.

98. Chen G, Wu D, Guo W, Cao Y, Huang D, Wang H, et al. Clinical and immunological features of severe and moderate coronavirus disease 2019. J Clin Invest. 2020;130(5):2620-9. https://doi. org/10.1172/JCI137244.

99. Deng Y, Liu W, Liu K, Fang YY, Shang J, Zhou L, et al. Clinical characteristics of fatal and recovered cases of coronavirus disease 
2019 in Wuhan, China: a retrospective study. Chin Med J (Engl). 2020;133(11):1261-7. https://doi.org/10.1097/CM9.0000000000 000824 .

100. Wang D, Yin Y, Hu C, Liu X, Zhang X, Zhou S, et al. Clinical course and outcome of 107 patients infected with the novel coronavirus, SARS-CoV-2, discharged from two hospitals in Wuhan, China. Crit Care. 2020;24(1):188. https://doi.org/10.1186/s1305 4-020-02895-6.

101. Shi S, Qin M, Cai Y, Liu T, Shen B, Yang F, et al. Characteristics and clinical significance of myocardial injury in patients with severe coronavirus disease 2019. Eur Heart J. 2020;41(22):2070 9. https://doi.org/10.1093/eurheartj/ehaa408.

102. Wang D, Hu B, Hu C, Zhu F, Liu X, Zhang J, et al. Clinical characteristics of 138 hospitalized patients with 2019 novel coronavirus-infected pneumonia in Wuhan, China. JAMA. 2020;323(11):1061-9. https://doi.org/10.1001/jama.2020.1585.

103. Aggarwal S, Garcia-Telles N, Aggarwal G, Lavie C, Lippi G, Henry BM. Clinical features, laboratory characteristics, and outcomes of patients hospitalized with coronavirus disease 2019 (COVID-19): early report from the United States. Diagnosis (Berl). 2020;7(2):91-6. https://doi.org/10.1515/dx-2020-0046.

104. Zheng Y, Xu H, Yang M, Zeng Y, Chen H, Liu R, et al. Epidemiological characteristics and clinical features of 32 critical and 67 noncritical cases of COVID-19 in Chengdu. J Clin Virol. 2020;127:104366. https://doi.org/10.1016/j.jcv.2020.104366.

105. Du RH, Liang LR, Yang CQ, Wang W, Cao TZ, Li M, et al. Predictors of mortality for patients with COVID-19 pneumonia caused by SARS-CoV-2: a prospective cohort study. Eur Respir J. 2020. https://doi.org/10.1183/13993003.00524-2020.

106. Violi F, Cangemi R, Romiti GF, Ceccarelli G, Oliva A, Alessandri F, et al. Is albumin predictor of mortality in COVID-19? Antioxid Redox Signal. 2020. https://doi.org/10.1089/ars.2020.8142.

107. Bonetti G, Manelli F, Patroni A, Bettinardi A, Borrelli G, Fiordalisi $\mathrm{G}$, et al. Laboratory predictors of death from coronavirus disease 2019 (COVID-19) in the area of Valcamonica, Italy. Clin Chem Lab Med. 2020;58(7):1100-5. https://doi.org/10.1515/ cclm-2020-0459.

108. Wan S, Xiang Y, Fang W, Zheng Y, Li B, Hu Y, et al. Clinical features and treatment of COVID-19 patients in northeast Chongqing. J Med Virol. 2020;92(7):797-806. https://doi.org/10.1002/ jmv. 25783.

109. Chen X, Yan L, Fei Y, Zhang C. Laboratory abnormalities and risk factors associated with in-hospital death in patients with severe COVID-19. J Clin Lab Anal. 2020. https://doi. org/10.1002/jcla.23467.
110. Xia P, Wen Y, Duan Y, Su H, Cao W, Xiao M, et al. Clinicopathological features and outcomes of acute kidney injury in critically Ill COVID-19 with prolonged disease course: a retrospective cohort. J Am Soc Nephrol. 2020;31(9):2205-21. https ://doi.org/10.1681/ASN.2020040426.

111. Zeng Z, Yu H, Chen H, Qi W, Chen L, Chen G, et al. Longitudinal changes of inflammatory parameters and their correlation with disease severity and outcomes in patients with COVID19 from Wuhan, China. Crit Care. 2020;24(1):525. https://doi. org/10.1186/s13054-020-03255-0.

112. Liu J, Dong YQ, Yin J, He G, Wu X, Li J, et al. Critically ill patients with COVID-19 with ECMO and artificial liver plasma exchange: a retrospective study. Medicine (Baltimore). 2020;99(26):e21012. https://doi.org/10.1097/MD.0000000000 021012.

113. Dickmann LJ, Patel SK, Wienkers LC, Slatter JG. Effects of interleukin 1beta (IL-1beta) and IL-1beta/interleukin 6 (IL-6) combinations on drug metabolizing enzymes in human hepatocyte culture. Curr Drug Metab. 2012;13(7):930-7. https://doi. org/10.2174/138920012802138642.

114. Rubin K, Janefeldt A, Andersson L, Berke Z, Grime K, Andersson TB. HepaRG cells as human-relevant in vitro model to study the effects of inflammatory stimuli on cytochrome P450 isoenzymes. Drug Metab Dispos. 2015;43(1):119-25. https://doi. org/10.1124/dmd.114.059246.

115. Guillen MI, Donato MT, Jover R, Castell JV, Fabra R, Trullenque R, et al. Oncostatin $\mathrm{M}$ down-regulates basal and induced cytochromes P450 in human hepatocytes. J Pharmacol Exp Ther. 1998;285(1):127-34.

116. Liptrott NJ, Penny M, Bray PG, Sathish J, Khoo SH, Back DJ, et al. The impact of cytokines on the expression of drug transporters, cytochrome P450 enzymes and chemokine receptors in human PBMC. Br J Pharmacol. 2009;156(3):497-508. https:// doi.org/10.1111/j.1476-5381.2008.00050.x.

117. Gregoire M, Le Turnier P, Gaborit BJ, Veyrac G, Lecomte R, Boutoille D, et al. Lopinavir pharmacokinetics in COVID-19 patients. J Antimicrob Chemother. 2020;75(9):2702-4. https:// doi.org/10.1093/jac/dkaa195.

118. Baldelli S, Corbellino M, Clementi E, Cattaneo D, Gervasoni C. Lopinavir/ritonavir in COVID-19 patients: maybe yes, but at what dose? J Antimicrob Chemother. 2020;75(9):2704-6. https ://doi.org/10.1093/jac/dkaa190. 